\title{
MICE \\ Absorber and Focus Coil Safety Working Group Design Document:
}

\author{
Preliminary Design and Assessments
}

December 4, 2003

\author{
Working Group Members \\ Giles Barr (Oxford) \\ Elwyn Baynham (Rutherford Appleton Laboratory) \\ Edgar Black (Illinois Institute of Technology) \\ Tom Bradshaw (Rutherford Appleton Laboratory) \\ Mary Anne Cummings (Northern Illinois University) \\ Michael A. Green (Lawrence Berkeley National Laboratory) ${ }^{\dagger}$ \\ Shigeru Ishimoto (KEK) \\ Yury Ivanyushenkov (Rutherford Appleton Laboratory) \\ Wing Lau (Oxford) \\ Michael Zisman" (Lawrence Berkeley National Laboratory)
}

${ }^{\dagger}$ Presently at Oxford

* Convener 


\section{INTRODUCTION}

A Neutrino Factory based on a muon storage ring is the ultimate tool for studies of neutrino oscillations, including possibly the discovery of leptonic CP violation. It is also the first step toward a muon collider. To develop a stored-muon-beam facility to serve as a Neutrino Factory, it is necessary to "cool" a muon beam (decrease its phase-space volume). The short lifetime of the muon, $2.2 \mu \mathrm{s}$ at rest, eliminates all currently demonstrated cooling techniques and requires that a new, heretofore untried, technique-ionisation cooling-be employed. Although ionisation cooling of muons has never been demonstrated in practice, it has been shown by end-to-end simulation and design studies to be an important factor both for the performance and for the cost of a Neutrino Factory. This motivates an international program of $R \& D$, including an experimental demonstration at Rutherford Appleton Laboratory (RAL). The aims of the international Muon Ionisation Cooling Experiment [!] are:

- To show that it is possible to design, engineer and build a section of cooling channel capable of giving the desired performance for a Neutrino Factory;

- To place it in a muon beam and measure its performance in various modes of operation and beam conditions, thereby investigating the limits and practicality of cooling.

The MICE collaboration has designed an experiment in which a section of an ionization cooling channel is exposed to a muon beam. This cooling channel assembles liquid-hydrogen absorbers providing energy loss and high-gradient radio frequency (RF) cavities to re-accelerate the particles, all tightly contained in a magnetic channel. It reduces the beam transverse emittance by $>10 \%$ for muon momenta between 140 and $240 \mathrm{MeV} / \mathrm{c}$.

The layout of the experiment is shown in Fig. 1-1. We utilize one complete magnetic cell of the cooling channel, comprising three absorber-focus-coil (AFC) modules and two RF-coupling-coil (RFCC) modules. Spectrometers placed before and after the cooling section shown in Fig. 1-1 perform the measurements of beam transmission and emittance reduction with an absolute precision of $\pm 0.1 \%$. The detector solenoids each have separate coils ("matching" coils) to tailor the optics smoothly between the cooling channel and detector modules. Details may be found in Ref. [!].

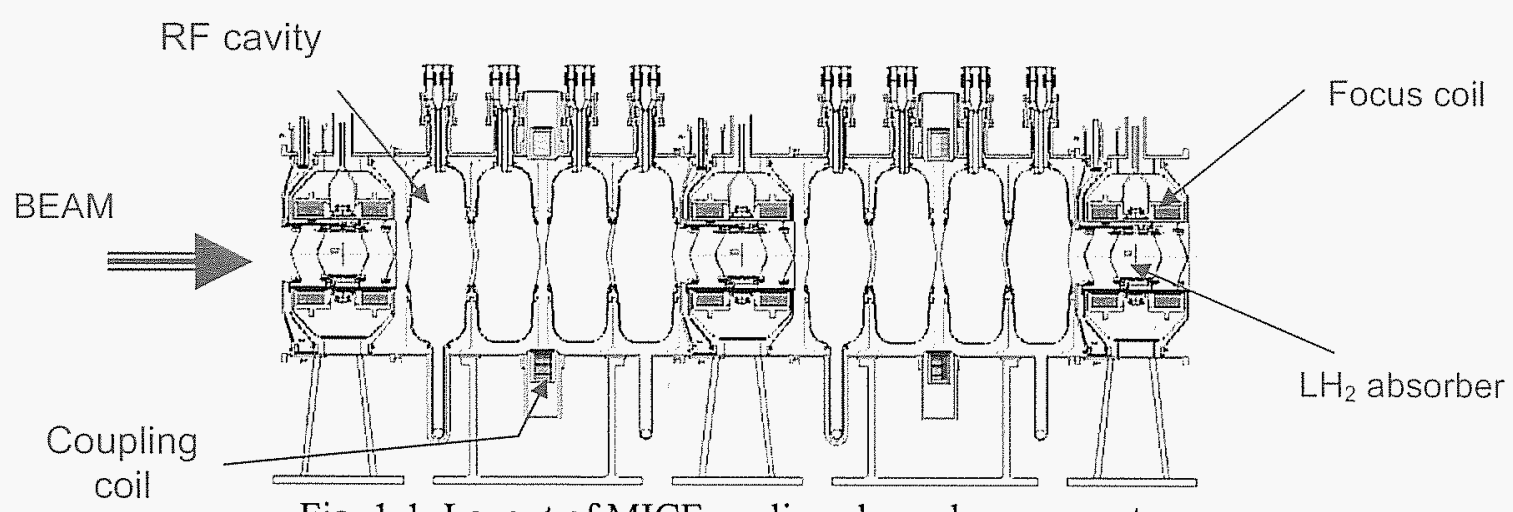

Fig. 1-1. Layout of MICE cooling channel components. 


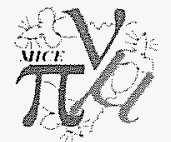

The requirement for liquid-hydrogen absorbers, justified in Section 3, brings with it significant safety issues that must be addressed. This report summarises the possible safety concerns and outlines our approaches to deal with them. As advised by Rutherford Appleton Laboratory management, we approach the MICE safety issues in stages. In the first stage, covered in this document, we describe our experimental requirements, delineate the possible hazards, and describe the features we intend to incorporate into the experiment to mitigate these hazards. After these concepts are reviewed and approved, we will proceed to the next stage-detailed design of the components and the safety system-in preparation for a second review by an external committee designated by RAL management. Only after successfully passing this second review, based on the specific implementation engineered in stage 2, will we begin fabrication of the actual absorber system.

Here we cover the concepts and approaches that we intend to follow, but not the engineering details that would be needed for final safety approval. This is the context in which the report should be interpreted and judged. Because of the close proximity of potential ignition sources to the hydrogen absorbers, designing a safe yet usable system is not trivial. The hydrogen safety approach we base our design upon is:

- Maintaining separation of oxygen and hydrogen atmospheres

- Avoidance of ignition sources in direct contact with hydrogen

These are actually redundant requirements - either of them is, in principle, enough to prevent an unsafe situation. However, as we consider the possibility of two off-normal conditions occurring simultaneously to be plausible, we account for it in our design approach. In particular, we adopt the following features in our design:

1. All containment and vacuum vessels are treated as "pressure vessels" according to standard mechanical engineering criteria (e.g., the American Society of Mechanical Engineers, ASME, or equivalent British Standard, BS, code). This was interpreted in our case to require that window thicknesses be specified to give a factor of four safety with respect to the design pressure. In addition, the windows are specified to tolerate 1.7 bar outside pressure without buckling.

2. Two layers of shielding are employed between the liquid hydrogen and possible contact with oxygen. All cryogenic surfaces below the oxygen freezing point are contained within the absorber vacuum safety envelope. Within this region, we employ an argon gas jacket on pipes that could potentially contact oxygen. Externally, we monitor for oxygen with sensors.

3. Separate vacuum volumes are provided for the RF cavities, the solenoids, and the absorbers. 
4. Hydrogen evacuation to a buffer tank is provided for the absorber and a corresponding ventilation system is provided to vent leaking hydrogen gas from the external storage system.

5. Detailed $R \& D$ activities for testing design concepts are planned. In addition, rigorous preassembly, testing, installation, and removal procedures are being developed. We will have pre-tested absorber units ready to install in case of a problem with an absorber during operation; repairs will not be attempted in situ.

In Section 2, we briefly describe the experimental facility at RAL where MICE will be staged. Section 3 indicates the critical parameters of the experiment and, in particular, justifies the need for liquid-hydrogen absorbers. Section 4 gives a technical description of the absorber assembly and the surrounding focusing coil system, along with an outline of the key integration issues. We also indicate the scope of the $R \& D$ program in support of the absorber design and summarise key results to date. Section 5 describes the hydrogen system and its operational parameters. Section 6 outlines the operational procedures we plan to follow in carrying out the experiment, and indicates the expected off-normal scenarios we envision and their consequences. The results of our preliminary HAZOP process are summarised in Section 7. This evaluation is necessarily at an early stage as there are many details of the system that are not yet specified. Nonetheless, it gives an indication of how we plan to evaluate the final system. Finally, a brief summary of this document is given in Section 8. 


\section{$\pi$}

\section{DESCRIPTION OF THE FACILITY}

The MICE experiment will be installed in Building R5.2 at RAL, a part of the ISIS accelerator complex, located between the ISIS linac hall (Building R5.1) and the ISIS control room (Building R5.5). It was built in the 1960s to host the initial linac and has recently been used for hosting a high energy physics beam facility. Figure 2-1 shows the location of building R5.2. It has about $560 \mathrm{~m}^{2}$ of floor space, a floor-to-ceiling height of about $8 \mathrm{~m}$ and a volume of about $4500 \mathrm{~m}^{3}$. The experimental area is equipped with two overhead cranes, each with a capacity of 8 tonnes.

The proposed MICE layout in Building R5.2 is shown in Fig.2-2. Both the beam line and the experiment will be located inside a radiation shielding enclosure. Space within the hall has been allocated for major services to detectors and the radio frequency (RF) system. A proposed position for MICE cryogenic plant, located next to building R5.2, is shown in Fig. 2-1. The layout of the hydrogen system components is described in Section 5.

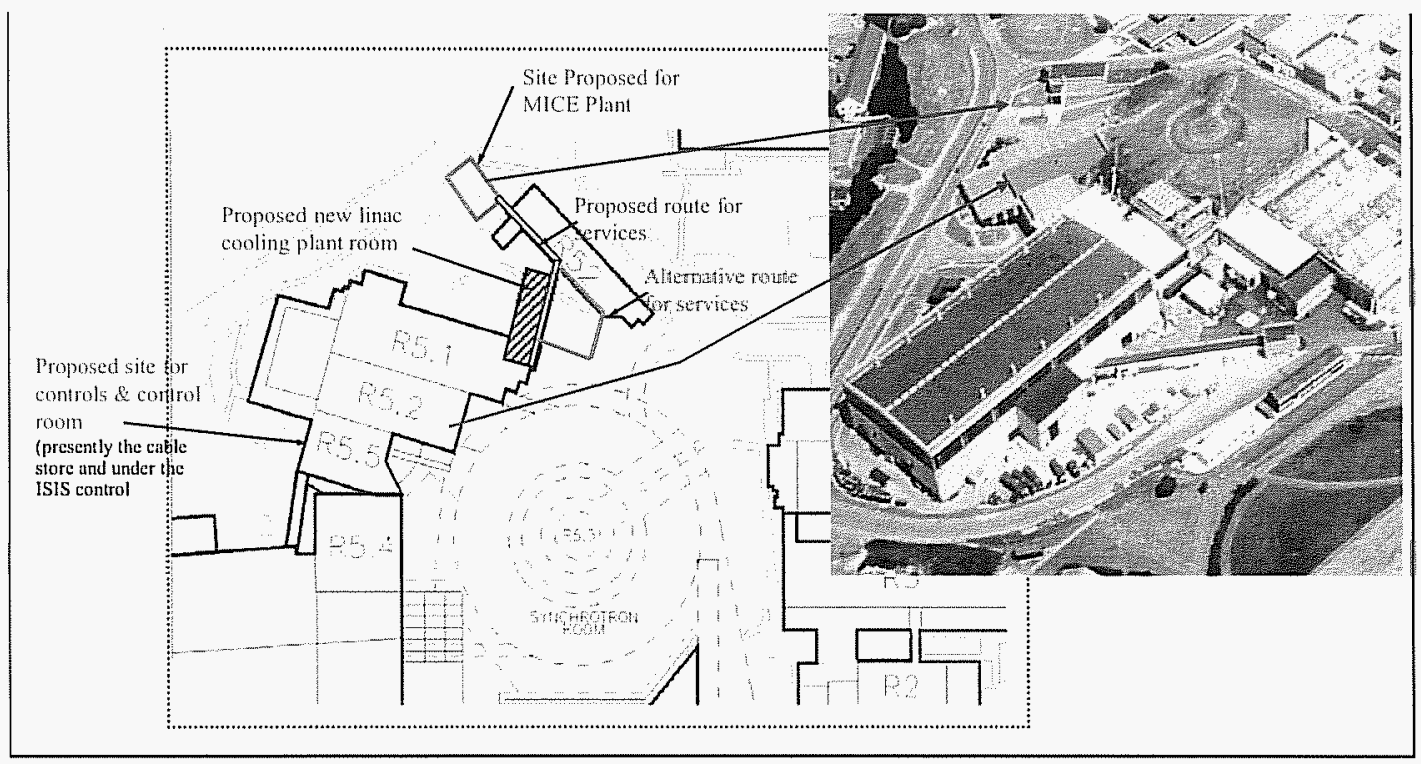

Fig. 2-1. Location of Building R5.2 at RAL. 


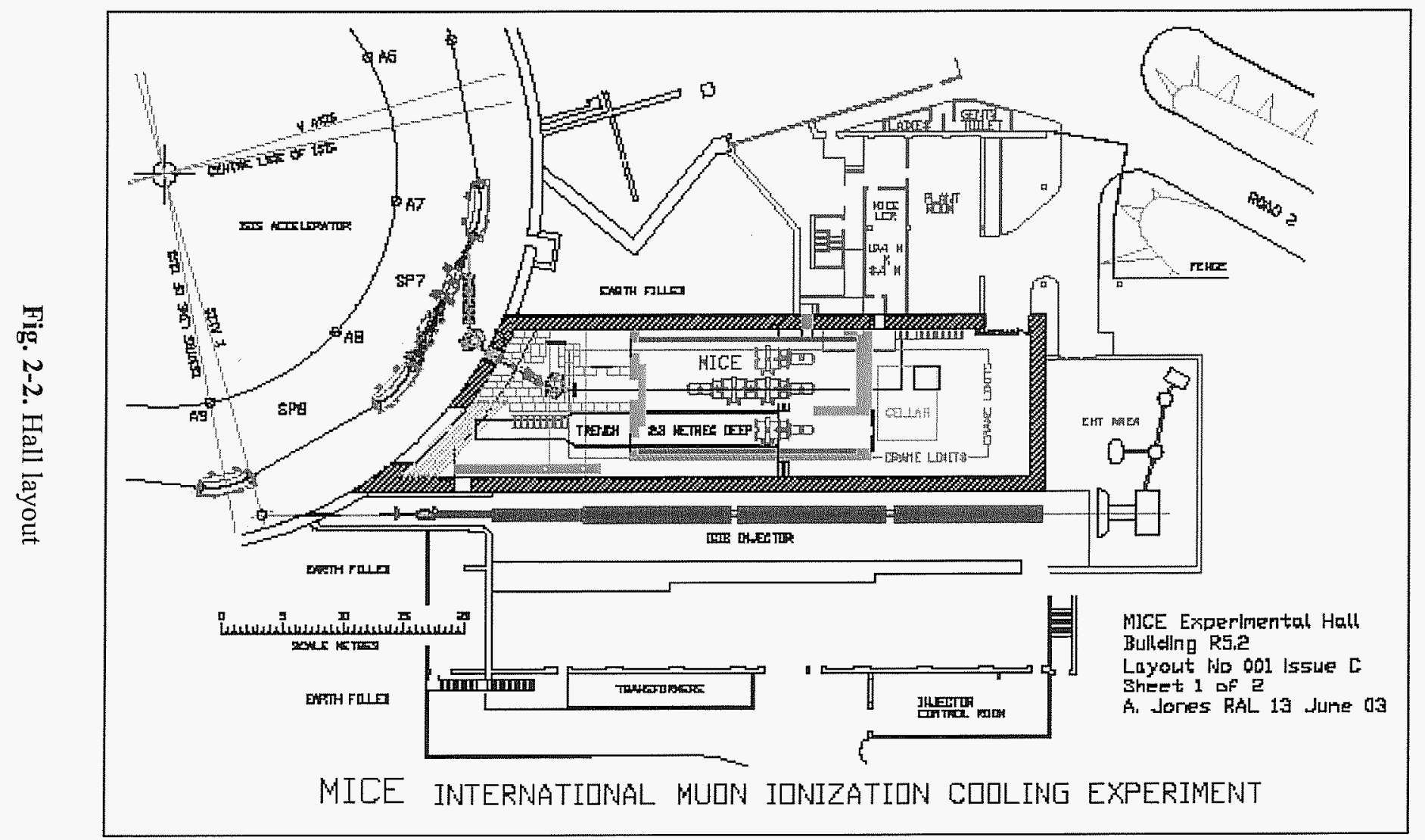




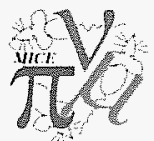

\section{CRITICAL PARAMETERS}

The purpose of the MICE experiment is to demonstrate the reduction of transverse emittance ("cooling") of a beam of muons using the technique of ionisation cooling. This technique is illustrated schematically in Fig. 3-1. Briefly, the muons pass repeatedly through absorbing material that decreases the momentum in all three directions $\left(p_{x}, p_{y}, p_{z}\right)$, followed by RF cavities that serve to restore the momentum only in the longitudinal $(z)$ direction. After repeating this many times, the transverse momenta $\left(p_{x}, p_{y}\right)$ are reduced compared with the longitudinal momentum, thus reducing the transverse emittance. As a practical matter, it is necessary to continually focus the muons to prevent the beam size from growing uncontrollably. This is accomplished by placing the cooling components in a strong solenoidal magnetic field. Thus, the MICE experiment requires absorbers (liquid hydrogen or other low- $Z$ materials), RF cavities, and superconducting coils in close proximity.

The main process that occurs as the muon beam traverses the absorber involves a large number of small-angle collisions with the atomic electrons. It is these collisions that decrease the momentum along the path of the individual muon. This is referred to as "ionisation loss" or $d E / d x$. There are also collisions with nuclei of the absorber material that produce a change in direction of the muon, which is referred to as "multiple scattering." Multiple scattering acts against the cooling process, and increases the angular spread of the particles. When the directions of the particles are very diverse, the beam emittance (i.e., the area in $x, p_{x}$ or $y, p_{y}$ phase space of the ensemble of particles) is said to be large. In principle, any material will cool if the resultant multiple scattering is small compared with the angular spread within the bunch. However at lower emittance, the multiple scattering becomes more important, and at some point, an equilibrium emittance is reached in which the amount of cooling caused by the ionisation loss and RF just balances the heating from

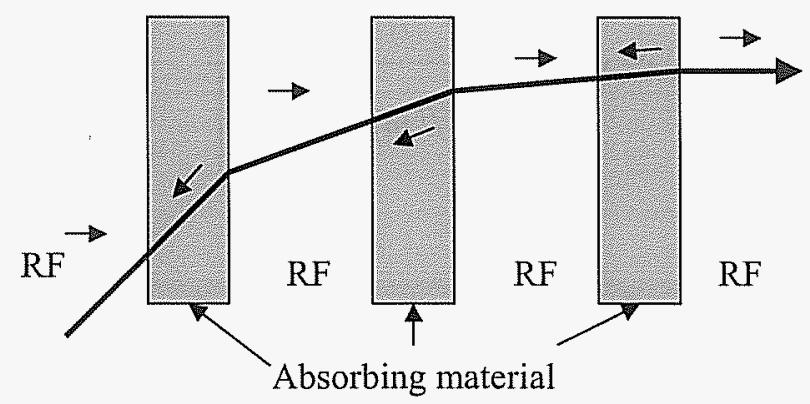

Fig. 3-1. Schematic of ionisation cooling scheme. The arrows indicate the gain or loss in momentum. In the absorbers, particles lose momentum along their trajectory; in the RF sections the momentum is restored only in the $z$ direction. 


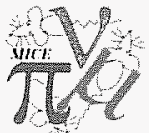

multiple scattering. This equilibrium emittance depends on the material and is lower for materials of lower atomic number $Z$. In practice, only materials of very low $Z$ are usable for cooling muons.

\subsection{Physics-driven specifications}

The physics of the muon interaction with material is what gives rise to the fundamental limitations to the realisation of muon cooling. All the techniques employed, such as the use of hydrogen, are driven by the need to overcome the fundamental limitations set by physical processes.

\subsubsection{Need for hydrogen absorbers}

As described above, the cooling process works as a competition between ionisation loss and multiple scattering. Since multiple scattering scales as $Z^{2}$, materials of low $Z$ can produce a lower equilibrium emittance, with hydrogen being the best of all. This is indicated by Eq. 3-1, which gives the approximate functional dependence of the cooling process in terms of the normalised emittance, $\varepsilon_{\mathrm{N}}$. The first term on the right hand side of Eq. 3-1 represents the cooling effect from ionisation loss and the second term represents the heating from multiple scattering. Here $\beta$ is the relativistic velocity, $\beta_{\perp}$ is the Twiss parameter at the absorber location (an inverse measure of the rms angular spread of the beam distribution), and $X_{0}$ is the radiation length, a measure of the multiple scattering. As noted earlier, the interplay between these terms leads to an equilibrium emittance, given in Eq. 3-2. From Eq. 3-2, it is clear that, in terms of the equilibrium emittance, the figure of merit for a particular choice of absorber material must scale inversely to the product $X_{0}\left|d E_{\mu} / d s\right|$. As this represents the equilibrium in only one transverse plane, we square this product to evaluate the merit factor in 4-dimensional phase $\operatorname{space}^{1}\left(x, p_{x}, y, p_{y}\right)$.

$$
\begin{aligned}
& \frac{d \varepsilon_{N}}{d s}=-\frac{1}{\beta^{2}}\left|\frac{d E_{\mu}}{d s}\right| \frac{\varepsilon_{N}}{E_{\mu}}+\frac{\beta_{\perp}(0.014 \mathrm{GeV})^{2}}{2 \beta^{3} E_{\mu} m_{\mu} X_{0}} \\
& \varepsilon_{x, N, \text { equil. }}=\frac{\beta_{\perp}(0.014 \mathrm{GeV})^{2}}{2 \beta_{m_{\mu}} X_{0}\left|\frac{d E_{\mu}}{d s}\right|}
\end{aligned}
$$

\subsubsection{Need for thin windows}

For a liquid absorber, we must employ solid windows to contain the material. To avoid degrading the equilibrium emittance too much, the containment windows should be made from a low- $Z$ material and be as thin as practical. (Clearly, it is the sum of the multiple scattering in the window plus absorber material that limits the ultimate performance of the system.) We have opted for using thin aluminium windows as the best choice considering strength at cryogenic temperatures, ease of manufacturing, and compatibility with liquid hydrogen.

\footnotetext{
${ }^{1}$ This is the merit factor, relative to that for hydrogen, that we include in Table 3-2.
} 


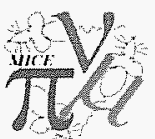

\subsubsection{Need for alternative absorbers}

Although we know that hydrogen produces the best possible effect, the MICE experiment will also measure other, safer, materials, as listed in Table 3-2. It is possible that future Neutrino Factory designs would contain hydrogen in only the downstream part of the cooling channel. (In the initial part of the cooling channel, where the beam emittance is well above the equilibrium emittance of hydrogen, another material could be used instead). We therefore want to measure a range of light materials including hydrogen.

Moreover, to demonstrate a full understanding of the cooling process, the MICE experiment must examine the performance of a range of absorbers. Measuring the equilibrium emittance in each case will show that we understand the process and that we have adequate control of possible systematic measurement errors.

\subsubsection{Cell length requirements}

The overall length of the cooling apparatus is constrained by the lifetime of the muons $(2.2 \mu \mathrm{s}$ at rest). We need to cool them before they decay. If travelling at the speed of light, a muon can travel for $660 \mathrm{~m}$ on average before decaying. Relativistic effects help this situation somewhat, but we cool at a relatively low momentum of about $200 \mathrm{MeV} / \mathrm{c}$. More importantly, the ability to cool rapidly is dependent on the ability to produce a low value of $\beta_{\perp}$ at the absorber location. For a given magnet strength, this is a function of the optical cell length. Based on Feasibility Study II [2], an adequate cell length for the initial part of the cooling channel is $5.5 \mathrm{~m}$. This configuration is what we have based the MICE design upon.

\subsubsection{Magnetic field strength requirements}

To reduce the deleterious effect of the multiple scattering, we design the solenoidal focusing to produce a tight focus at the point where the absorber is. At such a focus (a "low-beta" point), the angular spread of the particles is maximum, and therefore any induced increase from multiple scattering matters less. To efficiently produce a strong magnetic field on the axis of the experiment, the coils must be close to the beam axis radially. Otherwise, the stored energy in the magnet becomes very large, the forces on the superconductor become too large, and the superconducting magnet technology becomes too costly. This is also the reason why a compact liquid-hydrogen absorber is favoured over a gaseous hydrogen absorber-it can be placed at the focal point of the coils.

\subsubsection{RF gradient requirements}

The muons lose about $10 \mathrm{MeV}$ as they traverse one hydrogen absorber. Therefore to be able to apply cooling in a sequence of cells without a net loss of energy, the RF system in each cell must replace $10 \mathrm{MeV}$ of energy. This governs the total accelerating field per cell. For a given cell length, this places a premium on high electric field in the RF cavities. 


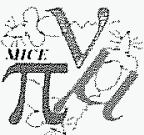

\subsection{Operational demands}

In addition to the above design constraints that result from fundamental physical limitations, the MICE design is also influenced by the desire to characterise a number of different configurations that will help to calibrate our design tools and ultimately permit us to choose the optimal configuration for a Neutrino Factory design. In the following subsections, the different field configurations are described and the list of absorber materials is given. To be able to complete the programme of measurements, there is a premium on fast changeovers, and this requirement has influenced the design of the apparatus. The most time-consuming changeover is the transition from liquid to solid absorbers (or between solid absorbers), since it requires a certain amount of dismantling and remounting of the experiment. This aspect will be covered in Section 4.2.

\subsubsection{Specification of field configurations needed}

Table 3-1 gives a list of different field configurations in the focus coils and in the other coils in the experiment. These configurations are from recent work done by Palmer on alternative operating modes for the MICE channel [3]. The SFOFO designation refers to the "flip" mode of operation (in which the field reverses direction within each absorber). The Semi-Flip designation refers to the case where there is no field flip in the centre of the cooling channel but only between detector solenoids and the cooling cells. The Non-Flip case corresponds to all solenoids, detector and cooling channel, having the same polarity. The different configurations allow: (1) a variety of muon energies; and (2) different beta functions at the absorber. Although similar current densities will be used in the non-flip operating mode, the fringe fields from the experiment will increase compared with the baseline flip configuration.

Table 3-1. Current densities for various operating configurations at the central momentum of $200 \mathrm{MeV} / \mathrm{c}$. The layout for the downstream half of the experiment, starting from the centre of the channel, is F1, C, F2, F3, M1, M2, E1, D, E2. Magnets designated F1, F2, F3 are focusing coils, $\mathrm{C}$ is the coupling coil, $\mathrm{D}$ is the detector main coil, and E1, E2 are the inboard and outboard end coils, respectively, used to improve field uniformity. M1 and M2 are the inboard and outboard matching coils between the focus coil and the detector, respectively. For each configuration, note that all focusing coils are run at the same current density and that only the polarity changes.

\begin{tabular}{|c|c|c|c|c|c|c|c|c|c|c|c|}
\hline & $\begin{array}{c}\text { beta } \\
\mathrm{cm}\end{array}$ & fils & $\begin{array}{c}\text { F1 } \\
\text { A/mum }\end{array}$ & $\begin{array}{c}C \\
A / m m^{2}\end{array}$ & $\begin{array}{c}\mathrm{F} 2 \\
\mathrm{~A} / \mathrm{mm}^{2}\end{array}$ & $\begin{array}{c}F * 3 \\
A / 1111^{2}\end{array}$ & $\begin{array}{c}M 1 \\
A / M m^{*}\end{array}$ & $\begin{array}{c}M 2 \\
A / m 1^{2}\end{array}$ & $\begin{array}{c}\text { E1 } \\
\mathrm{A} / \mathrm{mm}^{2}\end{array}$ & $\begin{array}{c}\mathrm{D} \\
\mathrm{A} / \mathrm{mm}^{2}\end{array}$ & $\begin{array}{c}\text { E2 } \\
A / 1 m m^{2}\end{array}$ \\
\hline$\triangle \mathrm{FOFO}$ & 43 & atelel & $106.01 T$ & 106.28 & 106.67 & -106.67 & -69.85 & -97.71 & -66.67 & -80.95 & -85.93 \\
\hline \multirow[t]{3}{*}{$+\ldots+\ldots$} & 25 & a1c:2el & 132.00 & 06.62 & 132.00 & -132.00 & -69.23 & -81.71 & -68.15 & -80.95 & -85.93 \\
\hline & 15 & $\operatorname{ac} 3 \times 1$ & 140.00 & 80.52 & 149.00 & $-14 t 9.00$ & $-6: 3.055$ & -69.70 & -69.933 & -80.95 & -85.933 \\
\hline & 7 & actel & 175.67 & 40.20 & 175.67 & -175.67 & -44.84 & 3.76 & -80.00 & -80.95 & -85.93 \\
\hline \multirow{2}{*}{$\begin{array}{l}\text { Somi-Flip } \\
++-\end{array}$} & 13 & de: & 58.33 & 96.62 & 90.00 & -00.00 & -88.58 & -55.08 & -72.50 & -80.95 & -85.93 \\
\hline & 25 & $\operatorname{dec} 20$ & 70.67 & 865.96 & $11: 3.3: 3$ & $-11: 3: 3: 3$ & -44.12 & -49.87 & $-72.5 !$ & -80.45 & -85.9 .3 \\
\hline \multirow{4}{*}{ Non-Flip } & 43 & ddiel & 58.333 & 96.62 & 58.33 & 58.3313 & $\$ 4.10$ & 90.67 & 62.22 & 80.95 & 85.93 \\
\hline & 25 & del2ol & 76.67 & 86.90 & 76.67 & 76.67 & 99.28 & 63.11 & 68.15 & 80.95 & $85 . ! 13$ \\
\hline & 15 & drisel & 95.00 & $76.4 !)$ & 95.00 & 95.00 & 52.94 & 17.73 & 72.59 & 80.45 & 85.913 \\
\hline & 7 & dulet & 113.67 & 45.00 & $11: 3.67$ & 113.07 & 60.90 & -3.73 & 77.04 & 80.95 & 85.9:3 \\
\hline
\end{tabular}




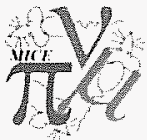

\subsubsection{Table of different absorber materials required}

The proposed list of materials is as follows: $\mathrm{LH}_{2}, \mathrm{LHe}, \mathrm{Li}, \mathrm{Be}, \mathrm{Al}$, and $\mathrm{CH}_{2}$. Table 3-2 gives the relevant parameters characterising ionisation $\operatorname{loss}^{2}\left(\langle d E / d x\rangle_{\min }\right)$ and multiple scattering $\left(X_{0}\right)$ for each material and a figure-of-merit (see Section 3.1.1) relative to liquid hydrogen.

As can be seen in Table 3-2, the figure of merit for hydrogen is almost twice that for helium, which is the next best possibility. As we increase $Z$, there is a marked decrease in the merit factor, reflecting the increasing dominance of multiple scattering in determining the equilibrium emittance. As noted earlier, while some compromise on the absorber material might be possible in the early stages of cooling, for the production of a muon beam that could be injected into a collider (so that two bunches collide head-on), hydrogen is the only option that can produce sufficiently low emittance beams.

Table 3-2. List of materials to be tested in MICE.

\begin{tabular}{lccl}
\hline Material & $\begin{array}{c}\langle\boldsymbol{d E} / \boldsymbol{d} \boldsymbol{x}\rangle_{\min } \\
\left(\mathrm{MeV} \mathrm{g}^{-1} \mathrm{~cm}^{2}\right)\end{array}$ & $\begin{array}{c}\boldsymbol{X}_{\mathbf{0}} \\
\left(\mathrm{g} \mathrm{cm}^{-2}\right)\end{array}$ & Merit \\
\hline Liquid $\mathrm{H}_{2}$ & 4.034 & 61.28 & 1 \\
Liquid He & 1.937 & 94.32 & 0.55 \\
$\mathrm{Li}$ & 1.639 & 82.76 & 0.30 \\
$\mathrm{Be}$ & 1.594 & 65.19 & 0.18 \\
$\mathrm{Al}$ & 1.615 & 24.01 & 0.02 \\
Plastic & $2.417^{31}$ & $46.22^{-1}$ & $0.20^{\text {al }}$ \\
\hline
\end{tabular}

Evaluated for $\mathrm{CH}_{4}$.

\footnotetext{
${ }^{2} \mathrm{We}$ evaluate the energy loss at the minimum of the ionisation curve, as this is typically close to where we operate a cooling channel.
} 


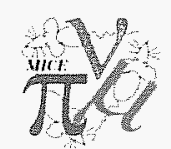

\section{ABSORBER/FOCUS COIL TECHNICAL DESCRIPTION}

The hydrogen absorber and focusing solenoid magnet will be mounted within a single module of MICE. The configuration of this module is shown in Figs. 4-1 and 4-2.

The focus coils are contained within a warm bore cryostat mounted in the outer vessel. The absorber unit is mounted mechanically within the solenoid warm bore, but in such a manner that it is essentially independent of the solenoid. Services for the solenoid, cooling and power, will enter through a dedicated turret in the outer vessel. Hydrogen feed/return, helium coolant, and vacuum connections to the absorber will likewise be via dedicated feeds through the outer vessel. The cryostat will be equipped with thermal radiation shields to reduce cryogenic heat loads.

Our design philosophy is to separate the two elements that comprise the absorber-focus-coil (AFC) module. This will ultimately impact favourably on the safety and reliability of the module in operation. Such separation leads to simplification of many steps, including design, fabrication, test, and commissioning. Indeed, once the envelopes and interfaces between the focus solenoid and the absorber element are defined, the design and all following stages can proceed with a high degree of independence. The focus solenoid can be fully fabricated and tested independently from the absorber unit. No further modification or dismantling of the solenoid will be necessary to install the absorber. Magnetic field measurements can be carried out within the warm bore and
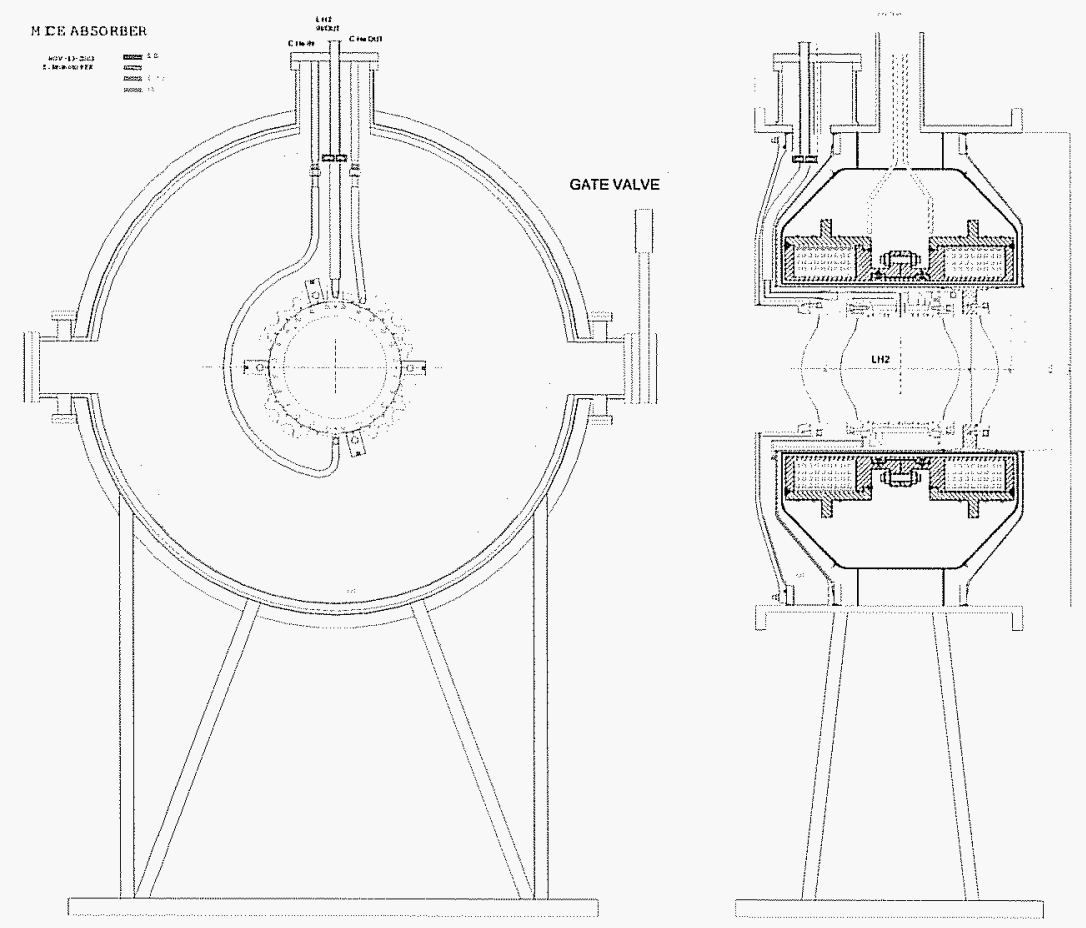

Fig. 4-1. Cross section (left) and side view (right) of the absorber/focus coil module. 


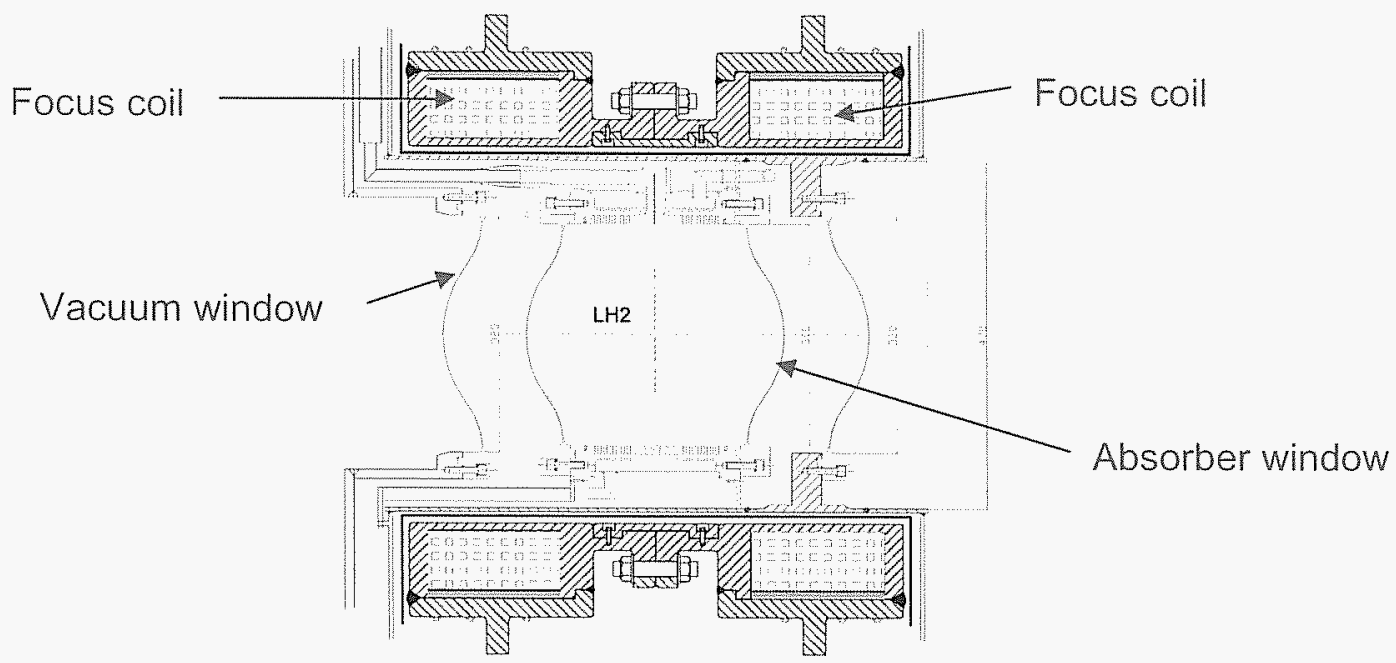

Fig. 4-2. Cross section of absorber body and heat exchanger.

referenced to the warm bore of the cryostat and the outer vessel shell. The hydrogen absorber can be assembled and fully tested as a complete unit before installation in the bore of the solenoid.

To minimise loss of experimental time, we plan to have spare absorber units completely assembled and tested. These will be individually stored in a dry-nitrogen atmosphere in a specially designed container.

Integration of the absorber with the solenoid will entail a mechanical mounting in the warm bore to pre-defined fiducial points and connection of the hydrogen, helium and vacuum lines. Removal of the absorber element from the solenoid will reverse the process. Installation and removal steps are detailed in Section 6.

The remainder of this Section is organised as follows. Section 4.1 introduces the liquid-hydrogen absorbers, Section 4.2 describes the focusing coil, and Section 4.3 describes how the solid absorber will be mounted in place of the liquid-hydrogen absorber when the experiment requires it. We give more details of the hydrogen absorber design in Section 4.4 and, finally, address the integration issues in Sections 4.5 and 4.6.

\subsection{Liquid-hydrogen Absorbers}

In Fig. 4-1, the absorber is shown mounted inside the focusing coils in the module. The absorber length is $35 \mathrm{~cm}$ and its diameter is $30 \mathrm{~cm}$. The hydrogen volume is $21 \mathrm{~L}$. The absorber is designed to use natural convection and an internal helium-gas-cooled heat exchanger to maintain a uniform temperature and remove heat from the absorber volume.

As noted, the absorber assembly design provides the ability to handle the assembly as a unit that can be inserted into, and extracted from, the bore of the focusing magnet for maintenance and experiment changeover operations. These operations will include changing the absorber medium 


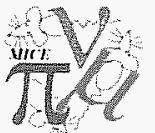

(e.g., liquid to solid absorbers) and perhaps instrumentation sensors inside the absorber container. The module cryostat provides the structural support for the absorber, the means for connections to external services, and vacuum insulation.

The absorber with its built-in heat exchanger is shown in Fig. 4-2. The absorber body and heat exchanger are made of aluminium. The windows are designed to be easily affixed to the absorber manifold using a bolted seal design. The absorber vessel is a cylinder machined from 6061-T6 aluminium alloy. It has a heat-exchanging surface in the form of fins that extend into the hydrogen volume inside and into a channel outside of the cylinder. A cover plate is welded on the outside, converting the channel into an annular duct for the flow of the helium gas coolant. The heat exchanger is carefully designed to minimise the temperature difference at the metal-liquid boundary. At the open ends of the cylinder are flanges where specially designed thin windows of the same aluminium material are hermetically sealed to complete the hydrogen containment. Flanged tubes of various sizes and thicknesses are welded to the hydrogen and helium volumes to permit connections to external cryogenics, vacuum, and instrumentation systems.

To help in satisfying the safety requirements, the absorber and all of its service pipework is enclosed in a vacuum-pumped volume (the "absorber vacuum space"). In order to keep the absorber vacuum space independent of all other MICE vacuum regions, a second set of windows ("vacuum windows") is installed in the beam path. This vacuum space envelops the absorber and its connecting ducts to serve as a safety barrier in case of an unlikely fault of the absorber or its connections. It also provides an effective vacuum insulation and oxygen barrier. The vacuum-toLH2 volume ratio is about 12:1 (not counting the volume within the connecting vacuum pipes), which provides a pressure-relief expansion buffer in case of an absorber window failure. In addition, safety relief valves in the vacuum pipes will promptly open to exhaust this flooded hydrogen volume, together with any hydrogen remaining in the absorber volume, into the system buffer volume without any contact with oxygen in the air.

The absorber vacuum space uses the warm bore tube of the focusing coil cryostat as its inner wall. As shown in Fig. 4-2, on one side, the vacuum window is mounted directly to the inner surface of the bore tube. On the other side, the vacuum window is attached to a large removable end plate. This plate is removed to facilitate the insertion or removal of the absorber assembly. Both vacuum windows are attached with a bolted seal to make their replacement straightforward should there be a window failure during the experiment.

Table 4-1 shows the normal operating parameters for the LH2 absorber. The hydrogen will be drawn as a gas from bottles to initially fill the hydrogen system, as described in Section 5. The refrigerant for the absorber heat exchanger is gaseous helium provided by the MICE refrigeration system.

Further details of the design of the hydrogen absorber are given in Section 4.4. 
Table 4-1. Parameters of $\mathrm{LH}_{2}$ absorber system. ${ }^{3}$

\begin{tabular}{lc}
\hline Liquid-hydrogen volume (at 20 K) [L] & 21 \\
Hydrogen volume (at STP) [L] & $\approx 17,000$ \\
Hydrogen length [mm] & 350 \\
$\mathrm{LH}_{2}$ operating temperature [K] & $14-21.9$ \\
$\mathrm{LH}_{2}$ operating pressure [bar] & $1.05-1.6$ \\
Max. heat removal ${ }^{\mathrm{a}}[\mathrm{W}]$ & 100 \\
Refrigerant mass flow [g/s] & $<20$ \\
Refrigerant inlet (outlet) temperature [K] & $14(<18)$ \\
Refrigerant inlet (outlet) pressure [bar] & $18(>1.3)$ \\
Absorber vacuum volume (within the module) [L] & 265 \\
\hline \multicolumn{2}{c}{ a) Design value; expected heat load in MICE is about $30 \mathrm{~W}}$.
\end{tabular}

\subsection{Focusing Coil}

Each focusing magnet assembly comprises a pair of superconducting coils as shown in Fig. 4-2. The coils will either be powered with opposite polarity to produce a magnetic field flip ("flip mode") or identical polarity to produce a solenoid field ("non-flip mode"). The two coils are assembled as a single unit with the magnetic forces carried by the aluminium alloy support structure at $4.5 \mathrm{~K}$. The coils will be cooled by circulation of two-phase helium in pipes on the support-structure surface.

The coil cold-mass assembly will be mounted in the cryostat vessel using low-heat-leak supports. These supports will carry the gravity load of the cold mass and also react the magnetic loads generated by interaction with the other magnets in MICE. The magnet cryostat will be integrated within the AFC module as shown in Fig. 4-1.

The absorber fits within the $782 \mathrm{~mm}$ long absorber-focus-coil (AFC) module. A space of $62 \mathrm{~mm}$ is allotted on one end of the module to provide room for the absorber piping; to accommodate this, the magnet centre and magnet cryostat centre are displaced $31 \mathrm{~mm}$ away from that end of the module. ${ }^{4}$ Table 4-2 lists the basic parameters of the focusing magnet and its cryostat.

Magnetic measurement must be performed in the warm bore of the finished magnet (before the absorber is installed) and at key fiducial points on the outside of the focusing magnet cryostat. The magnetic measurements on the finished magnet allow one to relate the magnetic field measured inside the bore of the magnet to the magnetic field that is measured at the fiducial points outside of the magnet. The outside measurements, which will be utilized exclusively once the module is installed in the MICE beam line, will permit determination of the field deviations at the $10^{-3}$ level.

\footnotetext{
${ }^{3}$ Values based on these parameters: $\mathrm{H}_{2}$ specific heat, $C_{p}$ (at $20 \mathrm{~K}, 1.2 \mathrm{bar}$ ), $9.5 \mathrm{~J} / \mathrm{g}-\mathrm{K}, \mathrm{H}_{2}$ thermal conductivity (at $20 \mathrm{~K}$, $1.2 \mathrm{bar}$ ), $98.6 \mathrm{~mW} / \mathrm{cm}-\mathrm{K}$, and $\mathrm{LH}_{2}$ density (at $20 \mathrm{~K}$ and $1.2 \mathrm{bar}$ ), $0.0712 \mathrm{~g} / \mathrm{cm}^{3}$.

${ }^{4}$ This asymmetry is shown in the right hand side of Fig. 4-1, though it is not very visible on that scale.
} 
Table 4-2. Basic parameters of the focusing module and solenoid magnet.

\begin{tabular}{|c|c|}
\hline Parameter & Value \\
\hline Inner vacuum vessel radius [mm] & 687 \\
\hline Outer vacuum vessel radius $[\mathrm{mm}]$ & 707 \\
\hline AFC module overall length [mm] & 782 \\
\hline Focusing magnet cryostat warm bore radius $[\mathrm{mm}]$ & 235 \\
\hline Focusing magnet cryostat outer radius $[\mathrm{mm}]$ & 707 \\
\hline Focusing magnet cryostat length $[\mathrm{mm}]$ & 720 \\
\hline Length available for absorber pipes [mm] & 62 \\
\hline Cold-mass inner radius $[\mathrm{mm}]$ & 250 \\
\hline Solenoid coil inner radius $[\mathrm{mm}]$ & 260 \\
\hline Solenoid coil thickness $[\mathrm{mm}]$ & 80 \\
\hline No. of coils in the focusing magnet & 2 \\
\hline Length of individual solenoid coil $[\mathrm{mm}]$ & 180 \\
\hline Longitudinal spacing between coils $[\mathrm{mm}]$ & 260 \\
\hline No. of layers per coil & 72 \\
\hline No. of turns per layer (each coil) & 109 \\
\hline Design current, flip mode ${ }^{\mathrm{it}}[\mathrm{A}]$ & 244.6 \\
\hline Avg. coil current density at design current ${ }^{11}\left[\mathrm{~A} \mathrm{~mm}^{-2}\right]$ & 133.3 \\
\hline Magnet self-inductance, flip mode $[\mathrm{H}]$ & $\sim 63$ \\
\hline Stored energy at design current & $\sim 1.9$ \\
\hline Peak field in winding at design current ${ }^{\prime \prime}$, flip mode $[\mathrm{T}]$ & 6.27 \\
\hline Design temperature margin at design current ${ }^{2}[\mathrm{~K}]$ & $\sim 1.1$ \\
\hline Inter-coil force at design current $[\mathrm{MN}]$ & 1.82 \\
\hline Peak cold-to-warm force at design current ${ }^{(a)}[\mathrm{MN}]$ & $\sim 0.30$ \\
\hline
\end{tabular}

\subsection{Solid absorbers}

Solid absorbers will consist of single, upright pieces of material that can be inserted into, and attached to, the inside of the focus coil warm bore (see Fig. 4-3). The vacuum and absorber windows are generally not required, nor is cooling. If need be, the isolation option provided by the vacuum windows could still be made available for a case in which there were a risk that a potential contaminant could be released into the vacuum environment of the cooling channel. No such need is presently anticipated.

The maximum anticipated heat load on the solid absorbers is not expected to affect the surrounding cryogenic systems. Thermal calculations for a solid target representative of the candidates listed in Table 3-2 indicate that a solid absorber with no active cooling will have a temperature rise of less than $70 \mathrm{~K}$. Calculations representing the specific targets and detailed configurations will be done when the final designs are specified.

As is the case for the liquid-hydrogen absorber, the solid absorber and its support system will be inserted and removed as a unit from inside the magnet bore. Longitudinal positioning of the solid absorber with respect to the magnet centreline will be done with respect to a properly located 


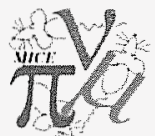

mechanical stop. The assembly of the solid absorber structure will be done on the bench, and any required certification procedures will be carried out prior to installation inside the magnet. (None of the planned solid absorbers has the combustion hazards of liquid hydrogen.) Care will be taken to ensure the structural stability of the absorber supports inside the high magnetic field.

\subsection{Absorber Design Details}

\subsubsection{Absorber window and vacuum window design and $R \& D$}

The development of thin aluminium windows to minimise multiple scattering is an ongoing activity of the MUCOOL Collaboration, whose members have devised a series of novel window designs that depart from the standard spherical and torispherical shells [4]. The absorber window design incorporates a spherical cap joined to the mounting flange via an inflected, tapered toroidal section. This inflected design achieves the same strength as the torispherical design used in Study II [2], but with less material. Therefore, the inflected design is considered superior to the design proposed in Study II and it will be used in MICE for both the absorber and the vacuum windows. An inflected window will be used for future MUCOOL R\&D activities, and it is anticipated that it would be the basis for follow-on Neutrino Factory design studies.

Window designs were developed and refined with extensive guidance from finite-element analysis (FEA) studies. As an example, we show in Fig. 4-4 results from the FEA study of a window with an inflected shape that is $34 \mathrm{~cm}$ in diameter and has a central thickness of $130 \mu \mathrm{m}$. Figure 4-4a

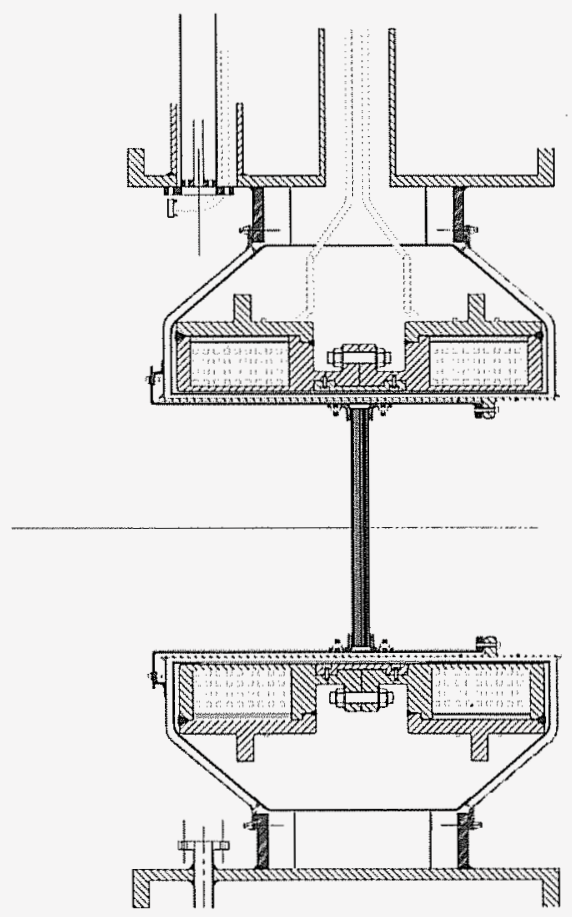

Fig. 4-3. Solid absorber assembly detail. 
shows the displacement of the window as a function of radius under internal pressurisation at the calculated burst pressure, 5.6 bar. Figure 4-4b shows the von Mises' stress at the junction of the window and the flange. Though the stress at the crown region is nearly uniform, the stress at the flange junction is mainly bending stress, indicating that the window would begin to leak prior to a full break. Figure 4-4c shows results of an FEA analysis for the same window under external pressurisation. No buckling is seen up to 2.3 bar of external pressure; beyond that pressure, the material begins to yield inelastically.

Proposed specifications for both the absorber and vacuum containment windows for MICE are given in Table 4-3. FEA studies of inflected windows for a variety of thickness values and diameters showed that the internal burst pressure and external yield pressures scale linearly with thickness and inversely with diameter; such scaling was used to obtain the thickness values in Table 4-3. Comparing the FEA results to the minimum pressure requirements for internal and external loading of vacuum windows, shows that the internal loading requirement is the more stringent and determines the needed thickness. Further FEA modelling of the actual windows to be built for MICE will be carried out before the final construction, as will an extensive series of destructive and non-destructive pressurisation tests of prototype windows.

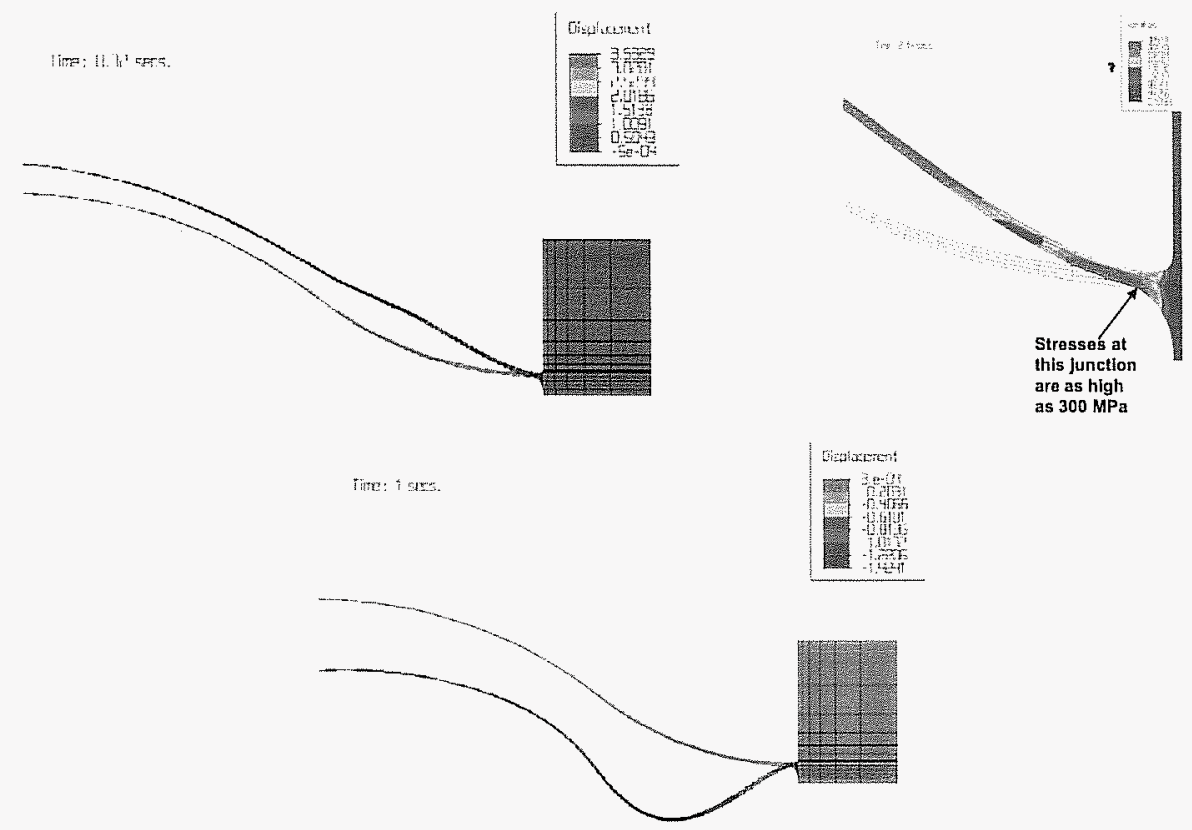

Fig. 4-4. Top: Predicted displacement (left) and stress (right) at the flange junction of a 34 $\mathrm{cm}$ window at burst pressure; for visibility, deflections have been represented on a greatly enlarged scale. Bottom: predicted displacement vs. radius of the $34 \mathrm{~cm}$ window unloaded (green) and under external pressurisation to 2.3 bar (various colours). 
Table 4-3. Absorber-assembly window specifications. ${ }^{\text {il }}$

\begin{tabular}{lcc}
\hline & Absorber window & Vacuum window \\
Material & 6061-T6 Al alloy & 6061-T6 Al alloy \\
Diameter $(\mathrm{mm})$ & 300 & 320 \\
Central thickness $(\mu \mathrm{m})$ & 180 & 190 \\
Min. burst pressure, internal loading (bar) & 6.8 & 6.8 \\
Min. buckling pressure, external loading (bar) & 1.7 & 1.7 \\
\hline ") Design pressure is 1.6 bar. &
\end{tabular}

To qualify our design, we require the thin aluminium windows to have a burst pressure above 6.8 bar at a temperature of $300 \mathrm{~K}$, roughly a safety factor of 4 above the design pressure. ${ }^{5}$ The process we envision is the same as that used for the earlier torispherical windows [5]. That is, we will carry out hydrostatic burst tests and verify the behaviour by comparing FEA calculations with photogrammetric measurements. Because the vacuum window must be designed to take pressure in either direction without buckling, we will experimentally verify window behaviour under external as well as internal load.

A minimum of four windows will be burst at a pressure above 6.8 bar. The measured burst pressure should agree to within a few percent with that calculated using finite-element methods. Photogrammetry [5] can be used to measure the deflection of the window while undergoing pressurisation tests, both in the elastic region and during the burst test (when the window is plastically deformed). One or two burst tests will be done with liquid nitrogen in the absorber. As noted earlier, the present analysis of the window suggests that a leak will develop before a full break occurs, meaning that no "shrapnel" will be produced when a window fails. If the first burst test indicates that the absorber window can fail in such a way that the vacuum safety window might also be damaged, the windows will be re-tested with a mesh in place to keep pieces from moving too far from the point of burst. ${ }^{6}$ At least one burst test will be done on a model absorber with its thin vacuum safety window in place.

R\&D will include testing to qualify the absorber and its helium cooling channels for use at their design pressure. Every absorber will be tested to 1.25 times the absorber design pressure. Based on our FEA studies, this means that the absorber and its windows will see strains that are within the elastic region during the entire hydrostatic test.

Our approach is to individually manufacture windows from single disks of aluminium alloy, using a numerically controlled lathe. At the present time, we are in the process of fabricating windows of the inflected design to test. Our FEA calculations of the proposed design indicate that the $500 \mu \mathrm{m}$ window thickness value used in the simulations presented in the MICE proposal [1] is certainly realistic, and indeed rather conservative.

\footnotetext{
${ }^{5}$ The "design" pressure is that at which the pressure relief device is set to operate, in our case, 1.6 bar.

${ }^{6}$ We would explore the possibility of, say, a Kevlar mesh to prevent an absorber window that has ruptured from breaking the vacuum window. For a Neutrino Factory, issues of radiation hardness would need to be assessed before choosing a material.
} 


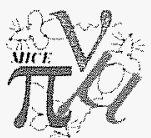

\subsubsection{Window seals}

As noted earlier, we use a bolted window design for both the absorber and vacuum safety windows. The seal will be indium. Based on the R\&D done at KEK, this seal is very robust under the conditions of temperature and pressure we require. Moreover, it is relatively inexpensive.

Because of the criticality of the window seal, we intend to carry out an R\&D program to develop an alternative welded window design in case of unanticipated problems with the baseline bolted design. We believe this to be prudent. Insofar as the bolted design meets our specifications, it will remain the technical choice for MICE.

\subsubsection{Certification procedure}

The focus coil magnets and their cryostats will be manufactured to the designs of the engineers at the Rutherford Appleton Laboratory and Oxford University. When welds on the magnet case carry the full repulsive forces (in the "flip" mode), they must be full penetration welds made by qualified welders to ensure that they are defect and porosity free. The welds will be tested with a dye penetrant to ensure that they are crack- and void-free. The weld preparation and the welds will be made in accordance with appropriate UK pressure-vessel standards.

The absorber and the absorber vacuum vessel will also be manufactured in accordance with the applicable pressure vessel codes and in accordance with any additional standards set forth by RAL. In particular, weld preparations and welds will be made in accordance with appropriate UK pressure-vessel standards. The welds will be done by qualified welders and will be inspected by qualified welding inspectors.

Leak checking will be carried out for the main elements of the MICE channel in accordance with accepted procedures. Table 4-4 summarises the acceptable leak rates for each location.

Certification will be required for parent materials used in component fabrication, for welding materials, for sealing materials, for pipes, and for transition pieces. The certificate must validate that materials have the required technical properties in the operating temperature range and that, if appropriate, they are compatible with hydrogen use. Monitoring equipment will likewise be certified intrinsically safe for use in a hydrogen area. Valid calibrations will be required for all

Table 4-4. Vacuum leak checking specifications.

\begin{tabular}{lc}
\hline Location & $\begin{array}{c}\text { Max. acceptable leak rate } \\
\left(\mathrm{mbar} \mathrm{L} \mathrm{s}^{-1}\right)\end{array}$ \\
\hline Absorber body & $10^{-9}$ \\
Absorber heat exchanger & $10^{-9}$ \\
Focus coil He tubes & $10^{-9}$ \\
Focus coil cryostat & $10^{-7}$ \\
RF cavities & $10^{-8}$ \\
Absorber safety vacuum & $10^{-7}$ \\
\hline
\end{tabular}

Measured at $300 \mathrm{~K}$. 


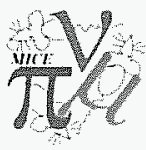

critical instrumentation, e.g., oxygen or hydrogen sensors, and a schedule for recalibration will be followed.

Acceptance testing will include a hydrostatic test of the absorber window at room temperature, pressure tests of the assembled unit (with windows), pressure tests of the vacuum windows and large end plate, and leak tests on all seal joints. Production tests on welds will also be carried out.

Prior to beginning fabrication of all components, a final safety review will be held by RAL. This review is expected to be carried out mainly by "external" experts. A final operational readiness review will be held after fabrication and assembly of the system. This review will verify the implementation of the approved design, including the certification of the materials and procedures used, and also the availability of suitable written procedures for operating the system.

\subsubsection{Interface with the magnet}

Here, we consider the interfaces and interactions between the absorber and the focus coils. The absorber will be mechanically mounted within the warm bore of the focus coil cryostat which will bear the small additional forces to support the mass of the absorber and its contents $(600 \mathrm{~N}$, corresponding to a $3 \mathrm{~g}$ load). The engineering interface between the focus coil warm bore and the absorber vessel will be designed to give precise location of the absorber unit in both axial and radial coordinates.

During normal operation, the focus coil will provide a static magnetic field in the absorber volume. There will be no forces generated on the absorber module in this mode, as the absorber is made totally from non-magnetic materials. During ramping (up and down) of the magnetic field, the slow change of field will result in very small eddy current generation in the absorber that will not affect its operation.

During a magnet quench, the rapidly changing field will generate significant eddy currents in the absorber module. These eddy currents have been modelled [6] using commercial software packages. This modelling has shown that a focus magnet quench will not produce significant power or force disturbances in the absorber. Indeed, the eddy current forces generated on the absorber windows are roughly two orders of magnitude below the working forces. The thermal consequences of a magnet quench (which are minor) are discussed in Section 6.6.7.

If it is not centred in the magnet, the absorber will experience longitudinal forces during a quench [6]. The supports will be designed to carry in excess of $2000 \mathrm{~N}$ in the longitudinal direction, which is the value of the force during a quench if the magnet were mis-centred by $8 \mathrm{~mm}$. In practice, of course, the supports will be constructed to prevent the absorber being mis-centred by more than 1$2 \mathrm{~mm}$. Mountings are required to minimise the heat transfer to the absorber, as discussed below.

The focus coils will be cooled and operated at full power before integration with the absorber. A full test procedure involving magnet quench and magnetic field survey will be executed. 


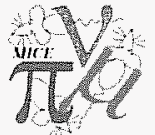

\subsubsection{Thermal considerations}

The absorber will be connected to the magnet warm bore through low-heat-leak supports that produce a total heat leak from $300 \mathrm{~K}$ to $20 \mathrm{~K}$ of less than $20 \mathrm{~W}$. Simple NEMA G-10 buttons can be used to position the absorber in the radial direction and should not contribute more than $4 \mathrm{~W}$ to this heat leak. The buttons allow the absorber to move as much as $0.8 \mathrm{~mm}$ in the radial direction when the system cools down, but this is not of much concern because a radial misalignment does not cause large forces on the absorber during a magnet quench.

A low-heat-leak support in the longitudinal direction, made from stainless steel screws and stacked washers of stainless steel and G-10, will carry the longitudinal forces from the absorber to a stainless steel ring on the inside of the magnet warm bore at the end away from the absorber piping. The thickness of the stainless steel and the G-10 in the stack will be adjusted to achieve the desired heat leak into the absorber. The heat leak from $300 \mathrm{~K}$ to $20 \mathrm{~K}$ in the longitudinal direction will be designed to be about $5 \mathrm{~W}$, and in any case should not exceed $15 \mathrm{~W}$.

The radiation heat load to the absorber window is expected to be about $10 \mathrm{~W}$. The absorber body will be insulated with a multi-layer insulation (MLI) blanket that is at least 10 layers. (As the absorber vacuum vessel is at room temperature, covering the hydrogen windows with a single layer of aluminised Mylar would reduce the radiation heat leak into the absorber by a factor of three. This would only add the equivalent of 10-12 $\mu \mathrm{m}$ of aluminium to the material thickness sampled by the muons.) The presence of MLI greatly reduces the heat flow into the absorber in the event the vacuum around the absorber degrades due to a small hydrogen leak.

In the event of a quench, power generation in the absorber body and windows will deposit $\sim 3 \mathrm{~kJ}$ of energy, which is available to heat the hydrogen liquid. This is only about $10 \%$ of the energy that would open the relief valve. There will be some boiling at the surface of the absorber but the hydrogen will be rapidly re-condensed.

The cooling power $Q$ of the absorber can be calculated as follows by assuming that the pressure drop and latent heat of the helium can be neglected:

$$
Q=m_{\mathrm{He}} C_{p}\left(T_{\text {out }}-T_{\text {in }}\right)
$$

where $m_{\mathrm{He}}$ is the helium mass flow rate $\left(\mathrm{g} \mathrm{s}^{-1}\right)$ and $C_{p} \approx 5.2 \mathrm{~J} \mathrm{~g}^{-1} \mathrm{~K}^{-1}$ is the specific heat for an ideal gas. For an inlet temperature $T_{\text {in }}=14 \mathrm{~K}$, outlet temperature $T_{\text {out }}=18 \mathrm{~K}$, and muon heating $Q$ $=100 \mathrm{~W}$ (considerably higher than anticipated in MICE, but comparable to the values envisaged in a Neutrino Factory), $m_{\mathrm{He}}$ is about $5 \mathrm{~g} \mathrm{~s}^{-1}$. This flow rate and cooling power are achievable using a standard refrigerator. Further information on the cooling of the absorber is given in Section 5.

Within the hydrogen volume itself, heat transfer occurs by natural convection. A computational simulation of natural convection, assuming beam heating as expected in a Neutrino Factory, has been performed as part of the MUCOOL R\&D program [7], and indicates that uniform temperature can be maintained within acceptable limits. The $\mathrm{LH}_{2}$ density changes from 0.077 at 14 $\mathrm{K}$ to 0.070 at $21 \mathrm{~K}$, almost linearly. Thus, the maximum $\mathrm{LH}_{2}$ density fluctuation is 0.007 , or $10 \%$, 


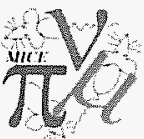

and the average effect seen by a muon will be even less. Study-II simulations showed negligible (few-percent) effects on cooling performance for average-density fluctuations of 5\% [2].

\subsection{Interface between AFC module and adjacent modules}

The AFC module will interface to other MICE modules through the end flanges of its outer vacuum vessel. The design of these flanges is critical to make the vacuum seal to the remainder of the MICE experiment (i.e., to the RF-coupling-coil, RFCC, module or the detector module), and to allow the removal of an AFC module for absorber change or maintenance. The forces between the focusing solenoid and the other magnetic elements within MICE must also be transmitted between modules ${ }^{7}$. Solutions to this involving either transmitting the forces across the flanges, or across other members included specifically for this purpose, are being considered. The plan is to have a common design for the interfaces to both the RFCC and detector modules, so that all three AFC modules are identical.

\subsection{Integration with experiment}

Detailed steps for the absorber installation into the focusing magnet warm bore are given in Section 6.1. The absorber assembly is designed as a fully independent unit that can be thoroughly tested before integration. All required absorber instrumentation will be contained within the module and used in the pre-integration tests. The basic elements, such as windows, absorber, and vacuum vessels, will be tested and qualified. Prior to integration, the complete absorber will be assembled and tested in a customised vacuum vessel. Such a vessel will allow full simulation of the operating conditions, both thermal and vacuum. The absorber volume will be filled with helium or nitrogen and thermally cycled. Throughout this process, highly sensitive leak monitoring will be carried out.

After this test stage, the absorber module will be packed for shipping. Special arrangements will be made for protection of the vacuum windows.

For the first complete module, the AFC cryostat will be equipped with end plates to allow a full operational test of the module before installation in MICE. This test will include:

- cooling down of the focus coil system with the absorber mounted

- cooling down the absorber unit and filling with helium

- quenching the focus coil magnet with helium in the absorber

- cooling down the absorber unit and filling with hydrogen

- evaluating the temperatures of the absorber vacuum windows

- experimental simulation of fault conditions

${ }^{7}$ Under working conditions, the maximum force to be transferred is 80 tonnes. 


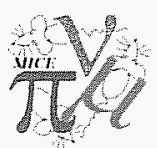

\section{HYDROGEN SYSTEM}

\subsection{System description}

The hydrogen system for the MICE absorbers is shown schematically in Fig. 5-1. The system is duplicated for each absorber.

\subsection{Safety features}

The design we propose includes the following safety features:

- Each of the hydrogen systems serves only one absorber to minimise the possibility of consequential failures

- Cryopumping surfaces that could be exposed to oxygen are avoided

- Hydrogen monitors and oxygen monitors are installed in each of the discharge volumes

- The amount of hydrogen is kept to a minimum

- The amount of hydrogen vented to the atmosphere is minimised

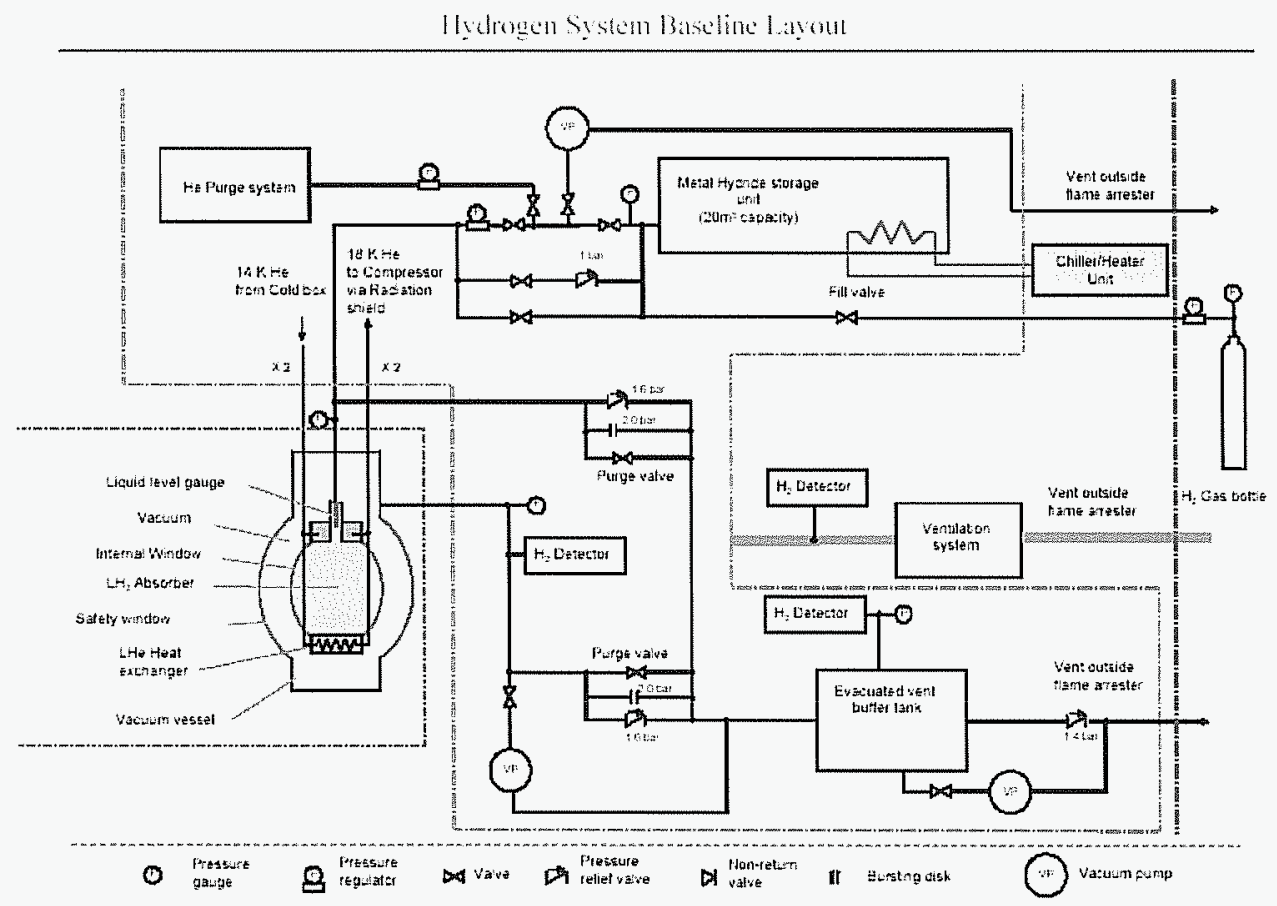

Fig. 5-1. Schematic diagram of the hydrogen system using metal hydride storage unit. 


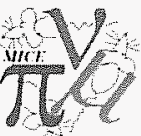

\subsection{System Components}

The main subsystems required for the hydrogen system include:

- Hydrogen storage system

- Hydrogen fill system

- Purge system

- Window failure safety vent system

Each of these systems is described below.

\subsubsection{Hydrogen Storage System}

Three options were initially considered for hydrogen storage for the MICE absorbers:

1. Hydride beds to absorb the gas and store it locally

2. Large storage vessels to passively contain the hydrogen

3. Gas bottles along with venting the hydrogen to air

After consideration of cost, packaging, and safety aspects, the choice of hydride beds was adopted.

\subsubsection{Hydride beds}

In our chosen design, the hydrogen is stored in hydride beds situated close to the absorber. These beds absorb hydrogen when cooled and release hydrogen when heated. The temperatures at which these processes take place depend on the hydride material but are generally near room temperature. Much work has been put into this technology for use in hydrogen-powered automobiles. The size of the storage tank for a MICE absorber depends on the material being used, but is expected to be about the size of a small desk. If there were a leak in the system when the hydride bed is cold, very little hydrogen would be evolved as it is bound to the hydride. This is a big advantage compared with conventional gas storage systems. The advantages of a hydride bed system are its compact size, its ability to almost completely empty the absorber at the end of a run, and its relative safety in the unlikely event of a leak or puncture of the system. The primary disadvantage of our choice is that the technology is new in this application.

\subsubsection{Potential Suppliers}

We have information on six or so firms that could potentially supply the system we need. We have contacted two of the most promising, Ovonics and Hera Hydrogen. Hera Hydrogen has already 


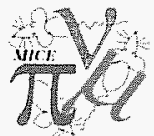

proposed some solutions they think would be suitable for our situation, and has indicated a reasonable price for a $20 \mathrm{~m}^{3}$ storage unit ${ }^{8}$.

\subsubsection{Hydrogen fill system}

While there are various options for this system, the simplest is to connect up a hydrogen gas bottle and fill the gas storage system to the required pressure. Bottles will be stored in a compound outside the hall.

\subsubsection{Purge system}

The purpose of the purge system is to remove all traces of hydrogen from the hydrogen system. The purge gas must be helium. (If any other gases contaminate the system there is a risk of blockage. It will not matter if there is a small amount of helium present in the hydrogen.) The helium can be used to leak test the absorbers after installation.

\subsubsection{Window failure vent system}

This emergency vent system is connected to the absorber vacuum space between the absorber and the vacuum windows. In the event of a rupture of the absorber window, it allows a safe path for venting the hydrogen gas.

The system consists of a pipe leading from the top of the absorber vacuum space ${ }^{9}$. This pipe leads through a low-pressure relief valve into a buffer volume that is sized to keep the pressure during the venting low. After this volume, a further relief valve leads to an external vent, outfitted with a flame arrester, on the roof of the building.

All external piping will be insulated to decrease the pressure drop along the pipe from the cold liquid and to prevent the exposure of cold surfaces that could serve to trap oxygen. Hydrogen monitors will be installed in the relief volume and in the piping to the absorber vacuum space to give adequate warning of a rupture.

\subsection{Technical Specification}

The physical size of the absorber is $400 \mathrm{~mm}$ in diameter by $350 \mathrm{~mm}$ in length (from window end to window end). The actual absorber body with its heat exchanger is $280 \mathrm{~mm}$ long. The hydrogen absorber body and windows will be fabricated from 6061-T6 aluminium. The absorber mass used for the cool-down calculation is $18.3 \mathrm{~kg}$.

\subsubsection{Cool-down of the absorber}

The heat removed from the absorber during a cool-down from $300 \mathrm{~K}$ to $20 \mathrm{~K}$ is about $125 \mathrm{~kJ}$ per $\mathrm{kg}$. Thus, cooling down an absorber requires that $2.3 \mathrm{MJ}$ of heat be removed. Cool-down of the absorber is dominated by the cool-down of the hydrogen in the absorber. The $21 \mathrm{~L}$ of hydrogen in the absorber has a mass of $1.5 \mathrm{~kg}$. The heat removed from the hydrogen includes the sensible heat

\footnotetext{
${ }^{8}$ This volume at STP corresponds roughly to the amount of hydrogen stored in a single absorber unit.

${ }^{9}$ Venting from the top reduces the risk of a plug of solid or liquid hydrogen forming during the venting process.
} 


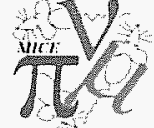

removed from $300 \mathrm{~K}$ to $20 \mathrm{~K}$, the heat of vaporisation of the hydrogen and the heat that must be removed to convert from the ortho state to the para state. The total heat that must be removed from the hydrogen is about $6.75 \mathrm{MJ}$. We conclude from the values below that an absorber can be cooled down and filled in a reasonable time.

The absorber cool-down naturally occurs in two phases:

1. The first phase is to cool the absorber body with helium entering it at $14 \mathrm{~K}$. Initially, the helium will leave the absorber at a temperature near room temperature, provided the heat transfer is efficient. The specific heat of helium gas, from $14 \mathrm{~K}$ to $300 \mathrm{~K}$, is $5.2 \mathrm{~J} \mathrm{~g}^{-1} \mathrm{~K}^{-1}$. At a mass flow of $5 \mathrm{~g} \mathrm{~s}^{-1}$, with the helium entering the absorber at $14 \mathrm{~K}$ and leaving at $300 \mathrm{~K}$, about $7.3 \mathrm{~kW}$ of cooling is delivered. As the absorber body cools down, less refrigeration is delivered. During the cool-down of the absorber body, about $4.2 \mathrm{~kW}$ of average cooling is delivered. As a result, the cool-down of the absorber body will be very rapid (of the order of 600 seconds for a helium mass flow of $5 \mathrm{~g} \mathrm{~s}^{-1}$ ).

2. The second phase is to condense the hydrogen. To liquefy one gram of hydrogen, $4.5 \mathrm{~kJ}$ of heat must be removed. This heat is removed by cooling and condensing hydrogen on the inside surface of the absorber. We envision pre-cooling the hydrogen with a liquid-nitrogen heat exchanger at $77 \mathrm{~K}$. This heat exchanger will remove $3.2 \mathrm{~kJ}$ per gram before the hydrogen reaches the condenser wall. As a result, the cool-down of the hydrogen in the absorber will be faster. Table 5-1 shows the estimated cool-down time and fill time for the absorber at two values of $14 \mathrm{~K}$ helium mass flow and with and (for comparison) without a liquid-nitrogen heat exchanger to pre-cool the hydrogen. As noted, the assumed absorber mass is $18.3 \mathrm{~kg}$, and the heat leak from the outside world is taken as $10 \mathrm{~W}$. During liquefaction, the helium enters the absorber at $14 \mathrm{~K}$ and leaves at $18 \mathrm{~K}$.

\subsubsection{Warm Up of the Absorber}

The absorber warm-up also occurs in two phases:

1. In the first phase of the warm-up, the $21 \mathrm{~L}$ of hydrogen in the absorber is boiled and returned to the hydride bed. Once the hydrogen in the absorber has become gaseous, it must be heated to nearly room temperature before it can be returned to the hydride bed. As will be seen below, the required capacity of the heater to take the hydrogen from $20 \mathrm{~K}$ to room temperature is limited in practice by the rate at which the hydrogen can be taken up by the hydride bed.

2. In the second phase of the warm-up, the absorber body is warmed to room temperature. The rate of warm-up of the absorber body is proportional to the heat that enters the absorber body from the outside world and from its attached heater. 
Table 5-1. Cool-down time for the absorber with and without a $\mathrm{LN}_{2}$ heat exchanger.

\begin{tabular}{lc}
\hline Cool-down operating condition & Cool-down time $(\mathrm{hr})$ \\
\hline No heat exchanger, $14 \mathrm{~K}$ helium flow $=5 \mathrm{~g} / \mathrm{s}$ & 20.3 \\
No heat exchanger, $14 \mathrm{~K}$ helium flow $=10 \mathrm{~g} / \mathrm{s}$ & 9.6 \\
No heat exchanger, $14 \mathrm{~K}$ helium flow $=20 \mathrm{~g} / \mathrm{s}$ & 4.7 \\
$\mathrm{~N}_{2}$ heat exchanger, $14 \mathrm{~K}$ helium flow $=5 \mathrm{~g} / \mathrm{s}$ & 6.4 \\
$\mathrm{~N}_{2}$ heat exchanger, $14 \mathrm{~K}$ helium flow $=10 \mathrm{~g} / \mathrm{s}$ & 3.1 \\
$\mathrm{~N}_{2}$ heat exchanger, $14 \mathrm{~K}$ helium flow $=20 \mathrm{~g} / \mathrm{s}$ & 1.5 \\
\hline
\end{tabular}

Table 5-2 shows the warm-up time for the case of an absorber with a $10-\mathrm{W}$ heat leak and no cooling (i.e., the worst-case scenario where there is a power failure) and the case where a heater attached to the absorber body delivers an additional $100 \mathrm{~W}$ to the body. When the absorber is warmed up in the normal course of operation, all of the hydrogen will be taken up by the hydride bed in the time shown under $\mathrm{LH}_{2}$ boil-off. From Table 5-2 it is clear that the absorber would warm up very slowly (18.4 hours) if there were a power failure. A $100-\mathrm{W}$ heater attached to the absorber, which we propose to adopt, permits a complete warm-up in less than 8 hours. However, at the full heater power, the hydrogen would be evolved too rapidly to be taken up by the hydride bed, and it would need to be vented through the flame arrester (see Fig. 5-1). We conclude that, with a heater in the 50-100 W range, the warm-up time for an absorber will not be an impediment to the replacing it in an orderly way.

\subsection{Location in hall}

As noted earlier, the storage of hydrogen as a metal hydride solid compound in a hydrogen bed is an attractive solution for MICE because of its compactness and safety aspects. A typical metal hydride hydrogen storage tank with $10 \mathrm{~m}^{3}$ of gas capacity is a cylinder with a diameter of about $300 \mathrm{~mm}$ and a length of $1 \mathrm{~m}$. Each MICE hydrogen absorber will require two such storage tanks, or possibly a single tank with $20 \mathrm{~m}^{3}$ capacity. In either case, a storage tank or tanks can be located near the absorber and connected to it as shown in Fig. 5-2. Both the storage tanks and buffer tanks are positioned under a hood connected to the ventilation system. This hood has extensions that cover the pipes between the absorber and the tanks and, as a result, if hydrogen leaks out it can easily be detected, collected, and vented outside the hall.

Table 5-2. Absorber warm-up times from $20 \mathrm{~K}$ to $273 \mathrm{~K}$, with and without auxiliary heater.

\begin{tabular}{lcccc}
\hline Warm-up operating condition & $\begin{array}{c}\mathrm{LH}_{2} \text { boil-off } \\
(\mathrm{hr})\end{array}$ & $\begin{array}{c}\text { Warm-up } \\
(\mathrm{hr})\end{array}$ & $\begin{array}{c}\text { Total } \\
(\mathrm{hr})\end{array}$ \\
\hline $10 \mathrm{~W}$ heat leak, heater $=$ & $0 \mathrm{~W}$ & 18.4 & $\sim 129$ & $\sim 147$ \\
$10 \mathrm{~W}$ heat leak, heater $=100 \mathrm{~W}$ & 1.7 & 5.5 & 7.2 \\
\hline
\end{tabular}



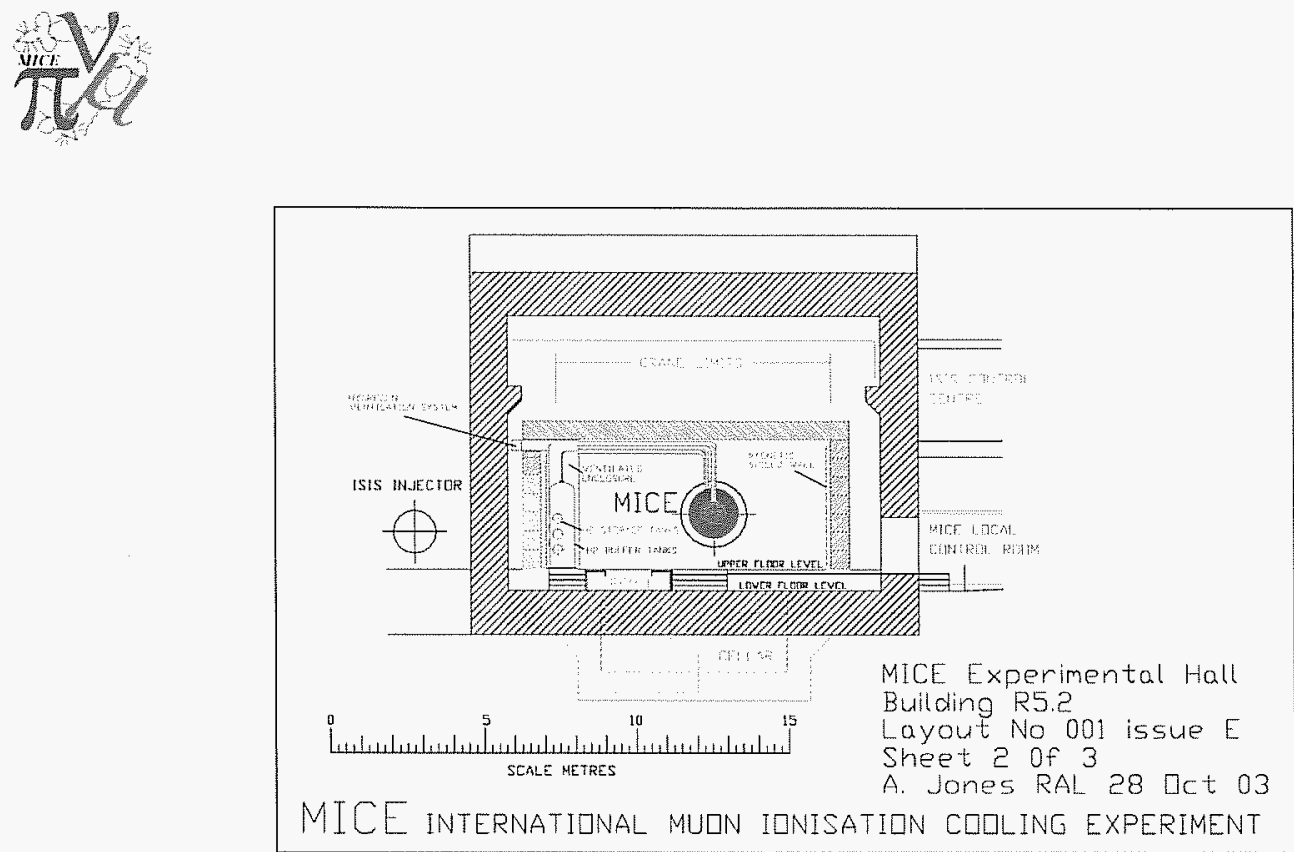

Fig. 5-2. Location of hydrogen storage system in MICE hall. A special ventilated enclosure is provided to house the metal hydride storage systems. 


\section{OPERATIONS}

\subsection{Installation and Testing of Hydrogen Absorbers}

\subsubsection{Pre-assembly and Testing}

The hydrogen absorber must be assembled, and pre-tested on the bench in accordance with the relevant pressure vessel code standards, before initial installation into the focusing solenoid. The required steps include:

1. Pressure test the absorber and its helium-cooling heat exchanger to the "standard test pressure" of 1.25 times the design pressure of the section of the absorber being tested. ${ }^{10}$

2. Cool down the absorber and fill with liquid nitrogen to verify cryogenic performance of seals.

3. Vacuum leak check the absorber hydrogen volume and the absorber helium cooling volume with a helium leak detector to a leak rate below $1 \times 10^{-9} \mathrm{mbar} \mathrm{L} \mathrm{s}^{-1}$.

4. Purge the hydrogen absorber with dry nitrogen and pressurise with dry nitrogen to an absolute pressure of 1.3 bar (19 psig).

5. Install multi-layer insulation around the absorber body.

Thereafter, until such time as it is installed into the focusing solenoid, the absorber will be protected from damage by carefully placing the tested assembly into its storage container.

\subsubsection{Installation into focusing coil warm bore}

The installation procedure for the absorber involves a number of testing steps to ensure that the absorber is leak tight prior to operating it with liquid hydrogen. The proposed procedure is as follows:

1. Purge the absorber and the helium heat exchanger with dry nitrogen gas.

2. Install the absorber into the magnet bore and connect it to the external helium pipes and hydrogen pipe.

3. Spray the joints with liquid nitrogen to reduce their temperature to about $100 \mathrm{~K}$.

4. Vacuum leak check the helium pipe connections and the hydrogen pipe connection to verify a vacuum leak rate below $1 \times 10^{-9} \mathrm{mbar} \mathrm{L} \mathrm{s}^{-1}$.

5. Pressurise the absorber body and heat exchange region with dry nitrogen at 1 bar.

6. Install the absorber vacuum vessel end plate onto the end of the focusing coil module. Verify that the fixed vacuum window is installed on the opposite side of the warm bore of the focusing magnet.

7. Pressurize the absorber vacuum space with dry nitrogen gas (and simultaneously the absorber itself) to 1.6 bar and hold for 10 minutes to make sure that the seals are tight.

\footnotetext{
${ }^{10}$ The standard test pressure is defined in British Standard 5500; design pressure for the absorber is 1.6 bar (23.5 psig). The design pressure for the absorber helium cooling circuit is 18 bar (265 psig).

${ }^{11} \mathrm{As}$ an alternative to step 3 , the absorber and the helium cooling jacket can be vacuum leak checked by pressurizing them with helium gas to a pressure of 1 bar and measuring the helium leak rate into the absorber vacuum space. The helium leak rate should not exceed $1 \times 10^{-9} \mathrm{mbar} \mathrm{L} \mathrm{s}^{-1}$.
} 
8. Evacuate the absorber vacuum space (and simultaneously the absorber itself) to below $0.1 \mathrm{~Pa}\left(7.5 \times 10^{-4}\right.$ Torr). Vacuum leak check the seals to verify a leak rate below $1 \times$ $10^{-7} \mathrm{mbar} \mathrm{L} \mathrm{s}^{-1}$.

9. Evacuate the absorber heat exchange region to $0.1 \mathrm{~Pa}$ (while the vacuum space remains evacuated to this pressure), back fill with dry Grade A helium gas to 1 bar, and measure the leak rate from the absorber heat exchange region to the absorber vacuum space. Then purge the heat exchange region and refill with dry helium gas.

10. Evacuate the absorber hydrogen region to $0.1 \mathrm{~Pa}$ (while the vacuum space remains evacuated to this pressure), back fill with dry Grade A helium gas to 1 bar, and measure the leak rate from the absorber hydrogen region to the absorber vacuum space. Then purge the absorber hydrogen region and refill with dry Grade A helium gas.

When the liquid absorber and the focus coil module is inserted into the MICE channel, the following steps should be taken:

1. Install the focusing module with absorber into the MICE channel and make up the seals between the adjacent modules.

2. Evacuate the MICE vacuum space on either side of the focus module to below $0.1 \mathrm{~Pa}$ and back-fill with dry nitrogen. Repeat the pump and purge of the MICE vacuum space.

3. Pump the absorber vacuum region to a pressure below $0.1 \mathrm{~Pa}$ and back-fill with dry nitrogen. Repeat the pump and purge of the absorber vacuum region.

4. Pump the helium cooling space and the hydrogen space in the absorber to a pressure below $0.1 \mathrm{~Pa}$ and back-fill with dry helium. Repeat the pump and purge of the helium cooling space and the hydrogen space in the absorber.

5. Pump the absorber, the absorber vacuum and the MICE vacuum space to a pressure below $0.1 \mathrm{~Pa}$. Vacuum leak check the MICE vacuum space on either side of the absorber to a leak rate below $1 \times 10^{-7} \mathrm{mbar} \mathrm{L} \mathrm{s}^{-1}$. $^{12}$

6. Purge, and pressurize to 1.1 bar with dry argon gas, the argon gas jacket around the absorber vacuum pipe. ${ }^{13}$

7. Cool down the absorber body using helium from the refrigerator. ${ }^{14}$

8. Open the valve between the absorber and the hydride bed and adjust the hydride bed temperature until hydrogen flows to the liquid absorber. The pressure in the liquid absorber during the filling process should be maintained at all times between 1.1 and 1.3 bar. Keep filling the absorber from the hydride bed until the liquid level gauge in the standpipe on top of the absorber indicates the presence of liquid hydrogen. ${ }^{15}$

\footnotetext{
${ }^{12}$ If the adjacent MICE vacuum space contains the RF cavities without multi-layer insulation, a minimum leak rate of $3 \times 10^{-8}$ mbar L s $^{-1}$ will be specified.

${ }^{13}$ If the absorber is to be filled with sub-cooled liquid helium, this step may be omitted.

${ }^{14}$ If the focusing module has been installed in the MICE channel, the focusing magnet may be cooled down at the same time the absorber is cooled down.

${ }^{15}$ Once the absorber is full, its pressure should be maintained between 1.1 and 1.3 bar.
} 
9. After the absorber is completely filled with liquid hydrogen, the magnet may be powered. ${ }^{16}$

\subsection{De-installation of the Hydrogen Absorber}

The process for removing the absorber from the MICE channel involves the following steps:

1. Turn off the helium cooling to the absorber and allow the absorber to warm up naturally for about 30 minutes. Adjust the temperature of the hydride bed so it is capable of reabsorbing hydrogen.

2. Turn on the absorber heater (attached to the absorber case) to boil away the liquid hydrogen and warm up the absorber body. Monitor the system pressure to verify that the hydride bed is taking up the hydrogen being released from the absorber.

3. Once the hydrogen absorber is warmed to $250 \mathrm{~K}$, close the valve between the absorber and the hydride bed. Evacuate the absorber to below $0.1 \mathrm{~Pa}$ (venting the pump through a flame arrester) and purge with dry nitrogen. Repeat the pump and purge cycle with dry helium. Keep the absorber filled with dry helium until it reaches ambient temperature.

4. Once the hydrogen absorber heat-exchanger space is warmed to $250 \mathrm{~K}$, close the valve between the absorber and the helium supply. Evacuate the absorber heat-exchanger space to below $0.1 \mathrm{~Pa}$ (venting the pump through a flame arrester) and purge with dry nitrogen. Repeat the pump and purge cycle with dry helium. Keep the absorber filled with dry helium until it reaches ambient temperature.

5. Back-fill the absorber vacuum volume to 1 bar with dry nitrogen and then pump to below $0.1 \mathrm{~Pa}$. Repeat purge and pump cycle with dry nitrogen, then fill again to $1 \mathrm{bar}$ with dry nitrogen.

6. Back-fill the vacuum spaces on either side of the focusing module with dry nitrogen to a pressure of 1 bar.

7. Break the seal between the focusing module and the adjacent modules and remove the focusing module from the MICE channel.

8. Break the vacuum seal on the large end plate of the absorber vacuum volume and remove the end plate.

9. Disconnect the hydrogen pipe and the two helium-cooling pipes from the absorber.

10. Carefully slide the liquid absorber from the focusing magnet bore, being careful to protect the absorber windows.

11. Carefully put the absorber assembly into its storage container.

After this, a new tested liquid absorber or a solid absorber may be installed into the focusing magnet. If a new or refurbished liquid-hydrogen absorber is to be installed into the focus magnet, the steps listed in Section 6.1.2 will be followed. If a solid absorber is to be installed into the focus magnet, a simpler procedure, listed in Section 6.3.1, will be used.

\footnotetext{
${ }^{16}$ If the absorber is being filled with liquid helium, the magnet may be charged at any convenient time.
} 


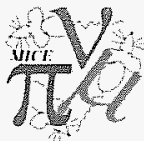

\subsection{Installation and Removal of Solid Absorbers}

Due to the lack of significant safety implications, the procedure for installing or removing a solid absorber is considerably simpler than that for a liquid-hydrogen absorber.

\subsubsection{Installation}

The steps required for installation of a solid absorber are as follows:

1. Install the solid absorber into the bore of the focus magnet, locating it longitudinally at the midplane between the two focusing coils (i.e., at the null point of the magnetic field when the magnet is powered in the flip mode). Secure the solid absorber to the magnet bore at this location.

2. Install the focus assembly into the MICE channel and make up the vacuum seals between the focus module and the adjacent modules.

3. Pump the MICE vacuum space to a pressure below $0.1 \mathrm{~Pa}$ and leak check on either side of the absorber to a leak rate below $1 \times 10^{-7} \mathrm{mbar} \mathrm{L} \mathrm{s}^{-1} .^{17}$

\subsubsection{Removal}

To remove a solid absorber from the MICE channel, the following procedure will be used:

1. Backfill the MICE vacuum on either side of the focusing module to be removed with dry nitrogen gas.

2. Break the vacuum seals and the force-carrying members between the adjacent modules and remove the focusing module from the MICE channel.

3. Disconnect the solid absorber from the magnet bore and remove the absorber.

4. Put the solid absorber in its storage container to protect it from damage.

\subsection{Normal operation}

The absorber will be operated in such a manner to ensure that the temperature remains at all times well above the triple-point of hydrogen, $T_{\mathrm{t}}=13.8 \mathrm{~K}$, to avoid the possibility of plugging the $\mathrm{H}_{2}$ pipe. To ensure this, the helium gas that cools the hydrogen has an inlet temperature of $14 \mathrm{~K}$ or higher.

To prevent other gases, in particular $\mathrm{O}_{2}$, from entering the $\mathrm{H}_{2}$ system, the $\mathrm{H}_{2}$ pressure is kept slightly above atmospheric pressure. To enforce this pressure limit, the $\mathrm{H}_{2}$ temperature at the liquid level must be higher than $20.4 \mathrm{~K}$. The high temperature limit on the hydrogen, $21.9 \mathrm{~K}$, comes from the design pressure specification of 1.6 bar for the absorber assembly. To measure the absorber temperature in this range we use temperature sensors that are calibrated and have well known behaviour in a high magnetic field. The accuracy of temperature measurement is better than $0.1 \mathrm{~K}$ over the range of $10-30 \mathrm{~K}$. The $\mathrm{H}_{2}$ pressure is also monitored, with an accuracy of less than $0.3 \%$ of the measured value.

\footnotetext{
${ }^{17}$ If the adjacent MICE vacuum space contains the RF cavities without multi-layer insulation, a minimum leak rate of $3 \times 10^{-8}$ mbar L s $^{-1}$ will be specified.
} 
We use a level sensor to measure the $\mathrm{H}_{2}$ liquid level. The $\mathrm{H}_{2}$ liquid level is set above the cooling channel volume (above the beam path), and lower than the maximum height in the $\mathrm{H}_{2}$ pipe. The absorber vacuum will be maintained below $1 \times 10^{-4}$ mbar during operation.

The $\mathrm{LH}_{2}$ absorbers are operated within these limits, which are summarized in Table 6-1. If the $\mathrm{H}_{2}$ temperature, pressure, or absorber vacuum exceeds its limits, the helium flow will be stopped and $\mathrm{H}_{2}$ gas will be recovered to the $\mathrm{H}_{2}$ tank.

\subsection{Magnet Operation}

Normal magnet operation has no adverse effect on the liquid-hydrogen absorbers. The heating rate into the absorber body during a charge or a discharge at the full voltage available from the magnet power supply $(10 \mathrm{~V})$ is from $0.014 \mathrm{~W}$ to $0.035 \mathrm{~W}$, depending on whether the magnet is operated in the flip mode (with the flux from the coils in opposition) or the non-flip mode. Clearly this heat source is small compared with the projected heat leak into the absorber by radiation and conduction $(<10 \mathrm{~W})$. The available refrigeration used to cool the absorber $(>50 \mathrm{~W})$ is more than sufficient to deal with the heat from the operating magnet. As the absorber vacuum vessel is at room temperature, heating of the absorber vacuum vessel parts due to magnet operation is even less of an issue. A quench of a superconducting focusing solenoid does affect the absorber, however, as will be discussed below (see Section 6.6.7).

\subsection{Off-Normal Conditions for the Hydrogen Absorber}

In this section we list the main off-normal conditions that are likely to occur and give an assessment of possible safety implications, if any.

\subsubsection{RF cavity vacuum or detector vacuum air leak}

A small air leak that does not affect the vacuum has no safety consequences as long as the RF or detector vacuum remains below $0.1 \mathrm{~Pa}\left(10^{-3} \mathrm{Torr}\right)$. If the pressure were higher than this, the RF cavities and detector would no longer be operable and MICE would be shut down until the leak is repaired.

A large leak into the RF cavity vacuum space or the detector vacuum space, such as might be caused by a failure of an electrical fitting or the accidental breaking of a valve or pipe, will have little in the way of safety consequences to the MICE absorber as long as the absorber vacuum window holds. Of course, such a leak will result in the experiment being shut down for a period of time until the leak can be found and repaired. If the RF cavity vacuum fails, the RF system will shut down within microseconds of detecting the failure. Even if the absorber safety window were

Table 6-1. Absorber Operation Limits.

\begin{tabular}{ll}
\hline $\mathrm{H}_{2}$ operating temperature range $(\mathrm{K})$ & $14.0-21.9$ \\
$\mathrm{H}_{2}$ liquid/gas surface temperature $(\mathrm{K})$ & $20.4-21.9$ \\
$\mathrm{H}_{2}$ pressure (bar) & $1.05-1.60$ \\
Absorber vacuum space pressure (mbar) & $<1 \times 10^{-4}$ \\
\hline
\end{tabular}




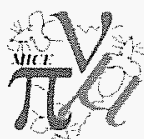

to break as a result of the initial failure, there would not be an ignition source present. Similar comments apply to the detector vacuum. In either case, the absorber would be emptied as quickly as possible, returning the liquid hydrogen either to the hydride bed or to the buffer tank, depending on the severity of the leak in the vacuum window.

\subsubsection{Absorber vacuum window leak}

The absorber vacuum vessel and its windows are designed in accordance with the pressure vessel code. Given the large sealing surface, however, small vacuum leaks in the absorber vacuum vessel can be expected to occur. As these small leaks are from one vacuum space to another, there will be a negligible amount of oxygen being frozen out on the absorber surfaces. Thus, the effect on either the performance of the absorber or its hydrogen safety is negligible.

A major failure of the absorber vacuum vessel would be an unexpected occurrence, but cannot be ruled out. The most likely time for this to occur is during pump down after installing, or reinstalling, an absorber module in MICE. The pump down procedure in Section 6.1.2, which requires purging and pumping the vacuum space, will easily detect a major breach of the vacuum window. It is conceivable, though unlikely, that the vacuum window fails during routine operation. In this case, we would be able to test for it periodically by using a small calibrated leak of a benign gas (e.g., $\mathrm{N}_{2}$ ) into the RF cavity or detector vacuum and looking for the released gas in the vacuum space with an RGA (residual gas analyser). ${ }^{18}$ If we do not find a better way to monitor the vacuum window integrity, this procedure will be adopted on a regular basis.

\subsubsection{Absorber leak}

Even though the absorber vessel and its helium cooling system are designed and vacuum leak checked to leak rates of below $1 \times 10^{-9} \mathrm{mbar} \mathrm{L} \mathrm{s}^{-1}$, small leaks could occur after repeated thermal cycling and/or pressure cycling. As long as the gas leak from the absorber to the absorber vacuum space is small, so that the absorber vacuum is less than $0.01 \mathrm{~Pa}\left(7.6 \times 10^{-5} \mathrm{Torr}\right)$ the absorber can operate properly. Its radiative heat leak would have an added term due to free-molecule conduction, but this would be manageable at low pressure.

If the leak from the absorber (either in the hydrogen part or the helium part) were large, there would not be enough refrigeration to maintain the hydrogen in the absorber as a liquid. In this case, the hydride bed would be cooled so that the hydrogen is reabsorbed. If the boil-off rate of hydrogen exceeds the rate of take up by the hydride bed, the pressure would build up until the hydrogen relief valve opens. The hydrogen would then be vented into the buffer volume and eventually to the air outside of the building.

\subsubsection{Hydrogen freezing}

Hydrogen could be frozen in the absorber only when the helium coolant enters the absorber at a temperature substantially below the triple-point temperature for hydrogen $(13.8 \mathrm{~K}$ for para-

\footnotetext{
${ }^{18}$ This procedure will certainly work if the absorber is "warm," that is, above the freezing point of the chosen monitoring gas. With a major breach, it would probably work even if the absorber is cold, but this would need to be tested in advance.
} 


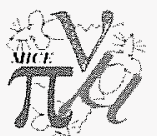

hydrogen) and when the heat flow into the absorber is small. The problem with frozen hydrogen in the absorber is that it interferes with the heat transfer across the helium-to-hydrogen heat exchanger. This could result in having frozen hydrogen at the bottom of the absorber while not providing enough heat transfer to keep the hydrogen at the top of the absorber from boiling. If the heat into the hydrogen exceeds the heat removed by the helium stream, the temperature and the pressure of the hydrogen will rise until the hydrogen is vented into the buffer tank.

As noted in Section 6.4, hydrogen freezing can easily be prevented by monitoring the temperature of the helium entering the absorber case and maintaining it at a temperature of $14 \mathrm{~K}$ or above. However, this is not completely straightforward. An example might be a case where the helium is expanded from 18 bar to a few bar before it enters the absorber. Although the 18 bar helium temperature might be well above $14 \mathrm{~K}$, the expanded helium gas is cooled by J-T cooling to a temperature that would be well under $14 \mathrm{~K}$. Thus, the control point for the helium refrigerant temperature must be located at a point that is after the helium has expanded to its final pressure.

\subsubsection{Large heat leak to the absorber}

A sudden change in the insulation that produces a heat leak rate greater than the rate of refrigeration is unlikely. The only plausible scenario for developing a leak that is larger than $100 \mathrm{~W}$ would be gas being admitted into the absorber vacuum volume. Moderate heat leaks into the absorber $(<200 \mathrm{~W})$ will result in hydrogen being boiled. Depending on the magnitude of the heat leak, this hydrogen will either go back to the hydride bed or be vented through the $1 \mathrm{~m}^{3}$ buffer tank.

The likely source of gas in the absorber vacuum volume is hydrogen or helium gas leaks from the absorber itself. For the geometry proposed for the absorber, and for either hydrogen or helium gas, the maximum heat leak into the absorber occurs at a pressure in the vacuum space of $1000 \mathrm{~Pa}$ (about 8 Torr). With either gas, the maximum heat flow into the absorber volume is about $0.15 \mathrm{~W}$ $\mathrm{cm}^{-2}$. For the MICE absorber, this translates to a total heat leak of about $900 \mathrm{~W}$, which boils off hydrogen at the rate of about $2 \mathrm{~g} \mathrm{~s}^{-1}$. As the absorber hydrogen piping is designed to handle much larger flows, the hydrogen in the absorber can be safely vented into the buffer tank and out the stack. At a boil-off rate of $2 \mathrm{~g} \mathrm{~s}^{-1}$, the absorber will be emptied of liquid hydrogen in about $750 \mathrm{~s}$.

Although a large gas leak from the RF cavity or detector vacuum space is conceivable, it is very unlikely to result in a large heat leak for the absorber. To do so, the leak would have to cause a rupture of the absorber vacuum safety windows, which have a buckling pressure under external load of 1.7 bar ( $25 \mathrm{psig}$ ). Even if a safety window did rupture, the hydrogen absorber vent and relief system is designed to handle resulting gas flow without increasing the pressure in the absorber above 2 bar.

A large heat leak into the absorber can also occur if there is a large leak from the argon cover gas into the absorber vacuum. In this case the argon gas would condense on the absorber body and then drip off. In this worst-case scenario, the heat transfer to the hydrogen is limited by film boiling of the hydrogen in the absorber. For a temperature difference of $70 \mathrm{~K}$, the film boiling heat transfer rate to the hydrogen is $\approx 3.0 \mathrm{~W} \mathrm{~cm}^{-2}$. The inside area of the absorber (including the 


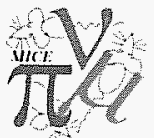

windows) is about $5900 \mathrm{~cm}^{2}$. For an absorber without multi-layer insulation, the peak heating of the hydrogen would be about $18 \mathrm{~kW}$, which boils the hydrogen in the absorber at the rate of $40.2 \mathrm{~g}$ $\mathrm{s}^{-1}$. If multi-layer insulation is installed around the absorber body, as we anticipate, the boil-off is reduced to about $11 \mathrm{~g} \mathrm{~s}^{-1}$. The two pipes between the absorber and its relief valve to the buffer volume are large enough (15 mm ID) to take this flow even when the hydrogen is at room temperature. If the absorber had argon condensing on its surface, it would be expected to empty in about 140 seconds.

\subsubsection{Loss of refrigeration or loss of electrical power}

A loss of electrical power and the resultant loss of refrigeration will lead to hydrogen evaporation from the absorber. The absorber system is designed for a heat leak of $10-20 \mathrm{~W}$ by radiation and by conduction from room temperature. At a $10 \mathrm{~W}$ heat leak, the absorber volume will be emptied of its hydrogen in 66000 seconds (about 18 hours). The hydride bed is able to accept the hydrogen gas at two or three times this rate at room temperature without added cooling. On loss of power, the valve between the absorber and the hydride bed will open automatically so that the hydrogen will begin to return to the hydride bed.

Loss of refrigeration will result in a steady increase in the absorber pressure. With a $10 \mathrm{~W}$ heat leak into the absorber, the absorber pressure will increase to the relief pressure of the absorber relief valve (assuming that the absorber is filled with liquid) in about $1800 \mathrm{~s}$. The hydrogen will be safely vented to the buffer tank. However, if action is taken immediately, that is, the valve to the hydride bed is opened within a few minutes of the loss of refrigeration, the hydrogen can be recovered by the hydride bed as in a loss-of-power event.

\subsubsection{Quench of the focusing solenoid}

A quench of the MICE solenoid puts about $13 \mathrm{~kJ}$ of energy into the absorber over a time period of 3-5 s. Very little of this energy ends up in the windows; most ends up in the absorber body. A transfer of $13 \mathrm{~kJ}$ will raise the temperature of the hydrogen in the absorber about $1.2 \mathrm{~K}$. If the hydrogen is at its saturation temperature at 1.1 bar, the pressure is the absorber will rise to 1.5 bar. If the hydrogen in the absorber is sub-cooled, the final absorber pressure is much lower. In either case, there is no problem from a safety standpoint.

The rate at which the absorber is re-cooled depends on the refrigeration available to do so. With 50 $\mathrm{W}$ of available refrigeration (above the static heat leak into the absorber), the hydrogen will be recooled to its original operating temperature in less than 5 minutes. The superconducting solenoid, however, will take several hours to cool down.

\subsubsection{Rupture of the hydrogen window}

The rupture of a hydrogen window is a very unlikely occurrence. The thin hydrogen windows and the absorber body have been designed in accordance with the applicable pressure vessel code. The relief system, set at 1.6 bar (23.5 psig), has also been designed in accordance with the applicable pressure vessel code. A small leak in the hydrogen window or its seal is a distinct possibility, however, as described in Section 6.6.3. 


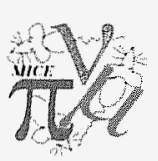

The relief system for the hydrogen absorber vacuum volume has been designed for the highly unlikely occurrence of a thin window rupture that floods the room temperature absorber vacuum chamber with the entire absorber contents of liquid hydrogen. In this case, the liquid hydrogen floods the lowest points in the absorber vacuum chamber to a depth of $250 \mathrm{~mm}$. This will put a thermal strain on the absorber vacuum vessel end and the magnet cryostat vacuum vessel. Both the absorber vacuum vessel end and the magnet cryostat are designed to withstand the thermal shock that would result from the $40 \mathrm{~K}$ temperature change in the absorber vacuum end plate and the 100 $\mathrm{K}$ temperature change that would occur in the magnet cryostat end plate. The flanges and the seal on the vacuum end plate see a much lower temperature excursion than either the absorber vacuum end plate or the magnet cryostat vacuum vessel.

If the hydrogen window ruptures, the room-temperature surface that sees the liquid hydrogen has an area of about $5500 \mathrm{~cm}^{2}$. The film-boiling heat transfer limit for hydrogen against a room temperature surface is about $9.3 \mathrm{~W} \mathrm{~cm}^{-2}$. The heat input into the $5500 \mathrm{~cm}^{2}$ liquid hydrogen area is thus $\approx 51 \mathrm{~kW}$. The $1500 \mathrm{~g}$ of hydrogen in the absorber will be boiled at a peak mass flow rate of about $116 \mathrm{~g} \mathrm{~s}^{-1}$. Most of the absorber liquid hydrogen will be boiled away in $20 \mathrm{~s}$. The minimum pipe size needed to carry the hydrogen gas away from the absorber vacuum volume has an ID of $60 \mathrm{~mm}$. The pipe and the rupture discs for the absorber vacuum system will be sized to handle $150 \mathrm{~g} \mathrm{~s}^{-1}$.

\subsubsection{Rupture of both the hydrogen and safety windows}

As the rupture of the hydrogen window is an extremely unlikely occurrence, a rupture of both windows is even less likely. The most plausible scenario that could cause the absorber safety window to rupture in concert with a hydrogen window rupture is "shrapnel" from the absorber window that hits the safety window. The primary role of the vacuum safety window is to keep frozen oxygen from building up on the surfaces of the absorber and on any pipes that have a temperature below the oxygen triple-point $(54.2 \mathrm{~K})$. Leaks from elsewhere that might provide oxygen for storage on the absorber and its pipes are prevented by an argon jacket at $1.1 \mathrm{bar}$.

Other potential leaks in the absorber vacuum system are from vacuum to vacuum. The rate of oxygen transport to cold absorber surfaces in such a scenario is extremely low. Hydrogen that goes through a rupture in the safety window will go into a region with a good vacuum. While such a region might have a source of ignition (for example sparking in an RF cavity or a detector), there is no oxygen present to cause the hydrogen to burn. A rupture of the absorber window and the safety window will cause MICE to be shut down.

The vacuum space into which the hydrogen vented must be pumped out very carefully. This can be done using the vacuum pump normally used for purging the absorber, which is vented to the outside through a flame arrester. If pumps for the MICE vacuum were used for this purpose, they too must be properly vented. We will examine the need for connecting all of the MICE vacuum pumps to a dedicated hydrogen exhaust system during the detailed design phase. As noted earlier. the vacuum system of MICE will not communicate directly with the ISIS vacuum system to eliminate the possibility that MICE vacuum problems could affect ISIS operation. 


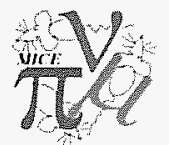

\subsection{Safety considerations and interlocks}

The hydrogen absorber system as set up here, is designed for "inherently" safe operation, that is, system parameters are maintained by basic physical principles and mechanical design. The redundant requirements of $\mathrm{H}_{2}$ and $\mathrm{O}_{2}$ separation, and absence of possible ignition sources in the vicinity of $\mathrm{H}_{2}$, have driven the design of the absorber-focus-coil system toward safe operation. In particular, the prevention of $\mathrm{O}_{2}$ freezing out on surfaces that contain, or could possibly come into contact with, $\mathrm{H}_{2}$, and separate containment volumes for the $\mathrm{RF}, \mathrm{LH}_{2}$ and magnet systems have determined the particular geometry and arrangement of the integrated system. 


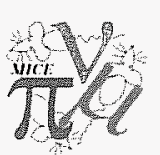

\section{PRELIMINARY HAZOP}

The Hazard and Operability analysis (HAZOP) is a well known technique to assess a plant's safety and operability. First introduced by engineers from ICI Chemicals in the UK in the $70 \mathrm{~s}$, this method entails the investigation of possible deviations from the design intention for a process facility. In HAZOP, a set of guidewords are used to examine deviations from normal process conditions at various key points (nodes) throughout the process. The guidewords are applied to the relevant process parameters as, for instance, temperature, pressure, etc., in order to identify the causes and consequences of deviations in these parameters from their intended values. Finally, the identification of unintended (or unacceptable) consequences results in recommendations for improvement of the process or the apparatus.

For the preliminary HAZOP study of the MICE hydrogen system the following nodes have been selected (as shown in Fig. 7-1):

- Hydrogen metal-hydride storage unit (Node 1)

- Hydrogen absorber internal vessel with hydrogen windows (Node 2)

- Hydrogen absorber vacuum jacket with safety windows (Node 3)

- Buffer tank (Node 4)

- Hydrogen enclosure (Node 5)

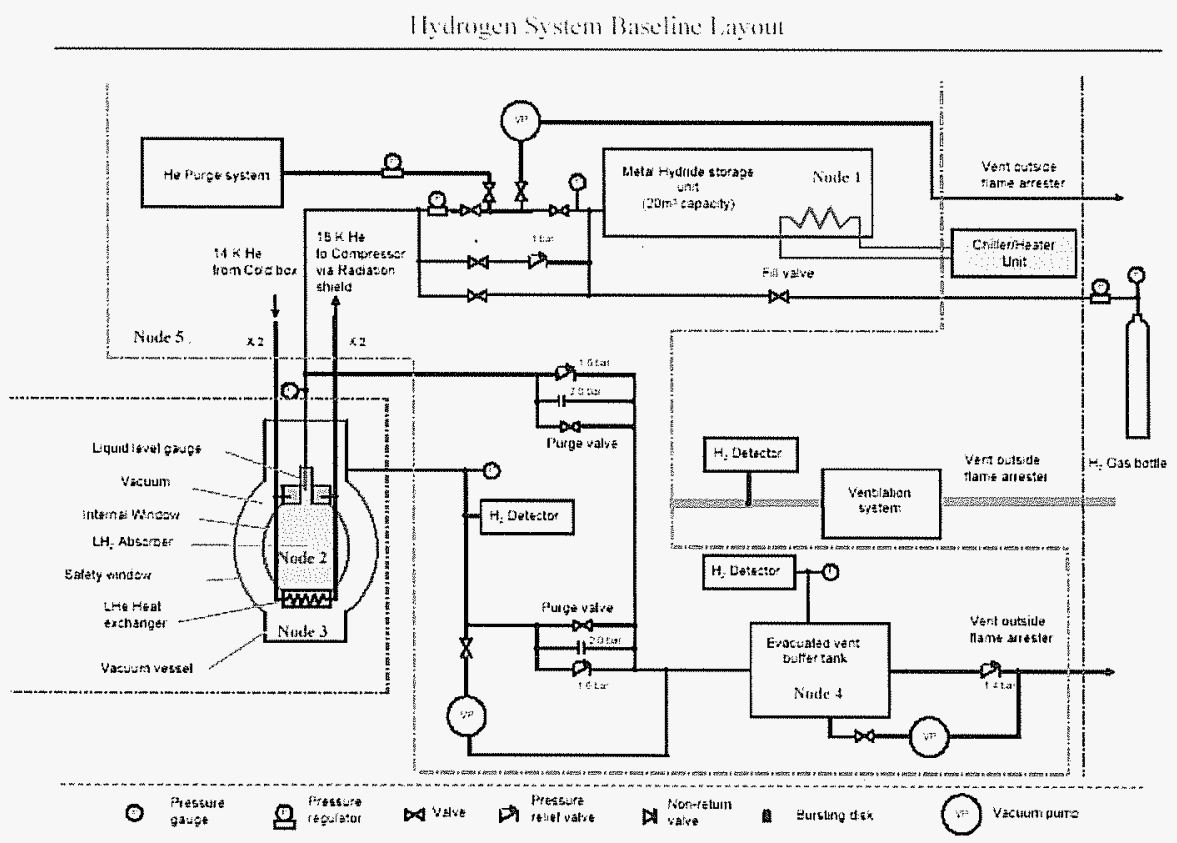

Fig. 7-1. Schematic diagram of the hydrogen system using metal hydride storage units (see Section 5). The node designations refer to the HAZOP process (see text). 
reliminary HAZOP worksheets are presented in Section 7.1. The results of the HAZOP are recommendations, which are summarized as follows:

- Hydrogen metal-hydride storage unit: implement an active pressure gauge, a pressure regulator, and a pressure-relief valve

- Hydrogen absorber vacuum jacket with safety windows: implement an active pressure gauge, a temperature sensor and additionally an active liquid-level meter

- Hydrogen absorber vacuum jacket with safety windows: implement an active hydrogen detector

- Buffer tank: implement an active pressure gauge and an active oxygen detector

- Hydrogen enclosure: implement a ventilation system with a hydrogen detector

As can be seen from the hydrogen system diagram in Fig. 7-1, many of the above recommendations are already implemented into the system design.

A final HAZOP of the MICE hydrogen system will be done after the design of both the hydrogen system and the absorber-focus coil pair assembly is finalized.

\subsection{HAZOP worksheets}

\subsubsection{Hydrogen metal-hydride storage unit (Node 1)}

Intent: To keep hydrogen gas in the tank - absorber vessel closed system.

\begin{tabular}{|l|l|l|l|l|l|l|}
\hline No & Parameter & Guide word & Cause & Consequence & Safeguards & Recommendations \\
\hline 1 & Pressure & Higher & $\begin{array}{l}\text { 1. Fill valve is accidentally } \\
\text { open or leaking. }\end{array}$ & $\begin{array}{l}\text { Pressure } \\
\text { regulator to } \\
\text { reduce pressure } \\
\text { in the line to } \\
\text { absorber. } \\
\text { windows can } \\
\text { break. }\end{array}$ & $\begin{array}{l}\text { Implement a } \\
\text { pressure regulator } \\
\text { in line to absorber. } \\
\text { Pressure-relief } \\
\text { valve to vent } \\
\text { outside. } \\
\text { Active pressure } \\
\text { gauge to trigger } \\
\text { an alarm. }\end{array}$ & $\begin{array}{l}\text { Implement a } \\
\text { pressure-relief } \\
\text { valve. }\end{array}$ \\
2. Tank is overheated. & $\begin{array}{l}\text { Implement an } \\
\text { active pressure } \\
\text { gauge. }\end{array}$ \\
\hline
\end{tabular}


7.1.2 Hydrogen absorber internal vessel with hydrogen windows (Node 2)

Intent: To keep hydrogen liquid inside hydrogen absorber module.

\begin{tabular}{|c|c|c|c|c|c|c|}
\hline No & Parameter & Guide word & Cause & Consequence & Safeguards & Recommendations \\
\hline 1 & Temperature & Lower & $\begin{array}{l}\text { Too much } \\
\text { cooling power } \\
\text { from the He } \\
\text { cooling system. }\end{array}$ & $\begin{array}{l}\text { 1. Pressure in the } \\
\text { hydrogen system } \\
\text { drops. }\end{array}$ & $\begin{array}{l}\text { Pressure gauge to } \\
\text { trigger an alarm. } \\
\text { Temperature } \\
\text { sensor to trigger } \\
\text { an alarm } \\
\text { Additional: } \\
\text { Liquid hydrogen } \\
\text { level sensor to } \\
\text { trigger an alarm. }\end{array}$ & $\begin{array}{l}\text { Implement both the } \\
\text { active pressure gauge } \\
\text { and the temperature } \\
\text { sensor. } \\
\text { Additional: } \\
\text { Implement an active } \\
\text { liquid level sensor. }\end{array}$ \\
\hline 2 & Temperature & Higher & $\begin{array}{l}\text { 1. Not enough } \\
\text { cooling power } \\
\text { from the He } \\
\text { cooling } \\
\text { system. } \\
\text { 2. Power cut. }\end{array}$ & $\begin{array}{l}\text { 1-2. Liquid } \\
\text { hydrogen } \\
\text { evaporates and } \\
\mathrm{LH}_{2} \text { level drops. } \\
\text { 1-2. Hydrogen } \\
\text { pressure rises. }\end{array}$ & $\begin{array}{l}\text { Temperature } \\
\text { sensor to trigger } \\
\text { an alarm } \\
\text { Additional: } \\
\text { Liquid hydrogen } \\
\text { level sensor to } \\
\text { trigger an alarm. } \\
\text { Pressure gauge to } \\
\text { trigger an alarm. }\end{array}$ & $\begin{array}{l}\text { Implement both the } \\
\text { active pressure gauge } \\
\text { and the temperature } \\
\text { sensor. } \\
\text { Additional: } \\
\text { Implement an active } \\
\text { liquid level sensor. }\end{array}$ \\
\hline 3 & Pressure & Lower & $\begin{array}{l}\text { 1. Window is } \\
\text { leaking or } \\
\text { broken. } \\
\text { 2. Pipe is } \\
\text { leaking. } \\
\text { 3. Hydrogen } \\
\text { tank is } \\
\text { leaking. } \\
\text { 4. Absorber is } \\
\text { over cooled. }\end{array}$ & $\begin{array}{l}\text { 1. Hydrogen } \\
\text { leaks into } \\
\text { vacuum vessel. } \\
\text { 2-3. Hydrogen is } \\
\text { leaking out. } \\
\text { 4. Pressure in the } \\
\text { system drops and } \\
\text { air can leak in the } \\
\text { system if the } \\
\text { system seal is } \\
\text { broken. }\end{array}$ & $\begin{array}{l}\text { Hydrogen } \\
\text { detector to trigger } \\
\text { an alarm. } \\
\text { Hydrogen } \\
\text { ventilation system } \\
\text { collects and vents } \\
\text { hydrogen. } \\
\text { Temperature } \\
\text { sensor to trigger } \\
\text { an alarm. }\end{array}$ & $\begin{array}{l}\text { Implement an active } \\
\text { hydrogen detector. } \\
\text { Implement hydrogen } \\
\text { collection and } \\
\text { ventilation system. } \\
\text { Implement a } \\
\text { temperature sensor. }\end{array}$ \\
\hline
\end{tabular}




\subsubsection{Hydrogen absorber vacuum jacket with safety windows (Node 3)}

Intent: To insulate the hydrogen vessel thermally and to provide an additional oxygen barrier.

\begin{tabular}{|c|c|c|c|c|c|c|}
\hline No & Parameter & Guide word & Cause & Consequence & Safeguards & Recommendations \\
\hline 1 & Pressure & Higher & $\begin{array}{l}\text { 1. Hydrogen } \\
\text { window is } \\
\text { broken. } \\
\text { 2. Vacuum pump } \\
\text { failure }\end{array}$ & $\begin{array}{l}\text { Hydrogen } \\
\text { bursts into } \\
\text { vacuum jacket. } \\
\text { Pressure slowly } \\
\text { increases. }\end{array}$ & $\begin{array}{l}\text { Pressure relief } \\
\text { valve to dump } \\
\text { hydrogen into a } \\
\text { buffer tank and } \\
\text { then to vent it } \\
\text { outside. } \\
\text { Monitor pressure } \\
\text { and have spare } \\
\text { pump. }\end{array}$ & $\begin{array}{l}\text { Implement vacuum } \\
\text { gauge with alarm and } \\
\text { have spare pump ready }\end{array}$ \\
\hline 2 & $\begin{array}{l}\text { Hydrogen } \\
\text { concentration }\end{array}$ & Higher & $\begin{array}{l}\text { Hydrogen leaks } \\
\text { due to broken } \\
\text { window. }\end{array}$ & $\begin{array}{l}\text { An explosive } \\
\text { mixture can be } \\
\text { formed if there } \\
\text { is an air leak as } \\
\text { well. }\end{array}$ & $\begin{array}{l}\text { Active hydrogen } \\
\text { sensor detects } \\
\text { hydrogen and } \\
\text { triggers an alarm. }\end{array}$ & $\begin{array}{l}\text { Implement an active } \\
\text { hydrogen sensor. }\end{array}$ \\
\hline
\end{tabular}

\subsubsection{Buffer tank (Node 4)}

Intent: To quickly relief pressure in the absorber module in case of window burst.

\begin{tabular}{|l|l|l|l|l|l|l|}
\hline No & Parameter & Guide word & Cause & Consequence & Safeguards & Recommendations \\
\hline 1 & Pressure & Higher & $\begin{array}{l}\text { 1. Venting } \\
\text { path is } \\
\text { blocked. }\end{array}$ & $\begin{array}{l}\text { Absorber vacuum } \\
\text { jacket windows can } \\
\text { break. }\end{array}$ & $\begin{array}{l}\text { Active pressure } \\
\text { gauge triggers an } \\
\text { alarm. }\end{array}$ & $\begin{array}{l}\text { Implement an active } \\
\text { pressure gauge. }\end{array}$ \\
& $\begin{array}{l}\text { 2. Tank is } \\
\text { leaking. } \\
\text { Buffer tank } \\
\text { unavailable for } \\
\text { dumping hydrogen } \\
\text { in case of accident } \\
\text { with absorber. }\end{array}$ & $\begin{array}{l}\text { Oxygen sensor } \\
\text { triggers an alarm. }\end{array}$ & $\begin{array}{l}\text { Implement an active } \\
\text { oxygen sensor. }\end{array}$ \\
& & $\begin{array}{l}\text { 3. Vacuum } \\
\text { pump failure. }\end{array}$ & & $\begin{array}{l}\text { Have a spare } \\
\text { pump. }\end{array}$ & Keep a spare pump. \\
\hline
\end{tabular}

\subsubsection{Hydrogen enclosure (Node 5)}

Intent: To localize and vent hydrogen in case of hydrogen leak.

\begin{tabular}{|c|c|c|c|c|c|c|}
\hline No & Parameter & Guide word & Cause & Consequence & Safeguards & Recommendations \\
\hline 1 & $\begin{array}{l}\text { Hydrogen } \\
\text { concentration }\end{array}$ & Higher & $\begin{array}{l}\text { 1. Hydrogen } \\
\text { leaks from } \\
\text { absorber module. } \\
\text { 2. Hydrogen } \\
\text { leaks from } \\
\text { hydrogen pipes. } \\
\text { 3. Hydrogen } \\
\text { leaks from } \\
\text { storage unit. }\end{array}$ & $\begin{array}{l}\text { 1-3. Explosive } \\
\text { oxygen- } \\
\text { hydrogen } \\
\text { mixture can be } \\
\text { formed }\end{array}$ & $\begin{array}{l}\text { Ventilation system } \\
\text { to quickly vent } \\
\text { hydrogen out. } \\
\text { Hydrogen detector } \\
\text { to trigger an alarm } \\
\text { and to start a high- } \\
\text { rate mode for the } \\
\text { ventilation system. }\end{array}$ & $\begin{array}{l}\text { Implement ventilation } \\
\text { system equipped with } \\
\text { hydrogen detector to } \\
\text { trigger high-rate } \\
\text { operating mode. }\end{array}$ \\
\hline
\end{tabular}




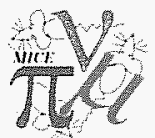

\section{SUMMARY}

In this document, we have described a preliminary design concept for the MICE absorber and focus coil system. Design challenges stem from the location of the absorbers-a confined space within a superconducting magnet and surrounded by RF cavities and/or detectors, both of which being potential ignition sources. Our approach separates the magnet and absorber designs by making a very clear boundary between them. This permits both designs to proceed essentially independently.

The design we propose is consistent with safety guidelines based on the redundant requirements of i) oxygen and hydrogen separation, and ii) avoidance of all ignition sources in the vicinity of the hydrogen. Our proposed approach reflects the underlying principle that the system must be failsafe even in the presence of two simultaneous failures. Even at this early stage, sophisticated finiteelement codes have been utilised in the evaluation of performance and safety margins.

Key features of the design with respect to safety are:

- Separate vacuum volumes for RF cavities, magnets, and $\mathrm{LH}_{2}$ absorbers

- Valved vents into external buffer tanks for hydrogen evacuation

- Window thickness values based on safety factors of 4 (with respect to design pressure) for both the absorber window and the vacuum safety window

Separate vacuum volumes for the magnet, $\mathrm{LH}_{2}$ absorber, $\mathrm{RF}$, and detector systems will maintain optimal temperatures for their respective operation, and avoid possible hazards in the event of a failure in any of them. In particular, the focusing-coil vacuum and absorber vacuum are separated to avoid magnet quenching in the case of a hydrogen system refrigeration failure, and to prevent $\mathrm{O}_{2}$ that might be frozen in the magnet super-insulation from contacting the hydrogen in the absorber. Our design eliminates the possibility of oxygen condensing anywhere inside the hydrogen vacuum or evacuation volumes.

A preliminary HAZOP process is now under way to evaluate hazards and develop recommended means to avoid them.

Assuming a successful outcome for the preliminary safety review, we will proceed to the detailed design phase, which will culminate in a final design review prior to commencing fabrication of the absorber and focus coil. 


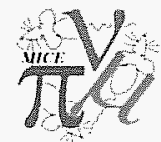

\section{REFERENCES}

[1] MICE Proposal, see http://mice.iit.edu/mnp/MICE0021.pdf.

[2] Feasibility Study-II of a Muon-Based Neutrino Source, ed., S. Ozaki, R. Palmer, M. Zisman, and J. Gallardo, BNL-52623 (2001); see http://www.cap.bnl.gov/mumu/studyii/ final_draft/The-Report.pdf.

[3] R. B. Palmer, http://mice.iit.edu/mnp/MICE0049.pdf.

[4] ASME Boiler and Pressure Vessel Code, ANSI/ASME BPV-VIII-1. American Society of Mechanical Engineers (New York, 1980), part UG-32.

[5] M. A. C. Cummings, et al., J. Phys. G $\underline{29}, 1689$ (2003).

[6] J. Rochford, E. Baynham, T. Bradshaw, I. Ivaniouchenkov, http://mice.iit.edu/mnp/MICE0010.doc.

[7] D. Kaplan, E. Black, K. Cassel, M. A. Cummings, see http://wwwmucool.fnal.gov/mcnotes/public/ps/muc0141/muc0141.ps.gz. 


\section{A. SUPPORTING DOCUMENTS}

M. A. Green, E. Baynham, G. Barr, W. Lau, J. Rochford, S. Yang, "Focusing Solenoids for the MICE Cooling Channel," http://mice.iit.edu/mnp/MICE0063.pdf.

M. A. Green, S. Ishimoto, W. Lau, S. Yang, "A Heat Exchanger between He Gas at 14-18K and Liquid Hydrogen at 20K," http://mice.iit.edu/mnp/MICE0062.pdf.

M. A. Green, E. Black, M. A. C. Cummings, D. Kaplan, S. Ishimoto, J. Cobb, W. Lau, S. Yang, R. B. Palmer, "The Integration of Liquid and Solid Muon Absorbers into a Focusing Magnet of a Muon Cooling Channel," http://mice.iit.edu/mnp/MICE0061.pdf.

M. A. Green, G. Barr, E. Baynham, J. Rochford, P. Fabbricatore, S. Farinon, R. B. Palmer, J.-M. Rey, "Superconducting Solenoids for the MICE Channel," http://mice.iit.edu/mnp/MICE0060.pdf.

M. A. Green, "Comments on Liquid Hydrogen Absorbers for MICE," http://mice.iit.edu/mnp/MICE0059.pdf.

M. A. Green, "The Superconducting Solenoid Magnets for MICE," http://mice.iit.edu/mnp/MICE0058.pdf.

M. A. Green, "The Cryogenic Refrigeration System for MICE," http://mice.iit.edu/mnp/MICE0057.pdf.

M. A. Green, J.-M. Rey, "Superconducting Solenoids for an International Muon Cooling Experiment," http://mice.iit.edu/mnp/MICE0056.pdf.

R. B. Palmer, "MICE Required Stay Clear," http://mice.iit.edu/mnp/MICE0044.pdf. 